\title{
Computational Study of the Impact of Unsteadiness on the Aerodynamic Performance of a Variable- Speed Power Turbine
}

\author{
Gerard E. Welch
}

Glenn Research Center, Cleveland, Ohio 


\section{NASA STI Program . . . in Profile}

Since its founding, NASA has been dedicated to the advancement of aeronautics and space science. The NASA Scientific and Technical Information (STI) program plays a key part in helping NASA maintain this important role.

The NASA STI Program operates under the auspices of the Agency Chief Information Officer. It collects, organizes, provides for archiving, and disseminates NASA's STI. The NASA STI program provides access to the NASA Aeronautics and Space Database and its public interface, the NASA Technical Reports Server, thus providing one of the largest collections of aeronautical and space science STI in the world. Results are published in both non-NASA channels and by NASA in the NASA STI Report Series, which includes the following report types:

- TECHNICAL PUBLICATION. Reports of completed research or a major significant phase of research that present the results of NASA programs and include extensive data or theoretical analysis. Includes compilations of significant scientific and technical data and information deemed to be of continuing reference value. NASA counterpart of peer-reviewed formal professional papers but has less stringent limitations on manuscript length and extent of graphic presentations.

- TECHNICAL MEMORANDUM. Scientific and technical findings that are preliminary or of specialized interest, e.g., quick release reports, working papers, and bibliographies that contain minimal annotation. Does not contain extensive analysis.

- CONTRACTOR REPORT. Scientific and technical findings by NASA-sponsored contractors and grantees.
- CONFERENCE PUBLICATION. Collected papers from scientific and technical conferences, symposia, seminars, or other meetings sponsored or cosponsored by NASA.

- SPECIAL PUBLICATION. Scientific, technical, or historical information from NASA programs, projects, and missions, often concerned with subjects having substantial public interest.

- TECHNICAL TRANSLATION. Englishlanguage translations of foreign scientific and technical material pertinent to NASA's mission.

Specialized services also include creating custom thesauri, building customized databases, organizing and publishing research results.

For more information about the NASA STI program, see the following:

- Access the NASA STI program home page at http://www.sti.nasa.gov

- E-mail your question via the Internet to help@ sti.nasa.gov

- Fax your question to the NASA STI Help Desk at $443-757-5803$

- Telephone the NASA STI Help Desk at 443-757-5802

- Write to: NASA Center for AeroSpace Information (CASI) 7115 Standard Drive Hanover, MD 21076-1320 


\section{Computational Study of the Impact of Unsteadiness on the Aerodynamic Performance of a Variable- Speed Power Turbine}

Gerard E. Welch

Glenn Research Center, Cleveland, Ohio

Prepared for the

50th Aerospace Science Conference

sponsored by the American Institute of Aeronautics and Astronautics

Nashville, Tennessee, January 9-12, 2012

National Aeronautics and

Space Administration

Glenn Research Center

Cleveland, Ohio 44135 


\section{Acknowledgments}

The author thanks Dr. Rodrick V. Chima (NASA) for expert assistance with his RANS tools, Michael Ni and Ron-Ho Ni of AeroDynamic Solutions, Inc. for technical assistance with the ADS tools, and Dr. John P. Clark (AFRL) for facilitating use of the AFRL Turbine Design and Analysis System (TDAAS) at NASA. This work was sponsored by the

NASA Fundamental Aeronautics Program (FAP), Subsonic Rotary Wing (SRW) Project.

This report contains preliminary findings, subject to revision as analysis proceeds.

Trade names and trademarks are used in this report for identification only. Their usage does not constitute an official endorsement, either expressed or implied, by the National Aeronautics and Space Administration.

Level of Review: This material has been technically reviewed by technical management.

Available from

NASA Center for Aerospace Information 7115 Standard Drive

Hanover, MD 21076-1320
National Technical Information Service 5301 Shawnee Road Alexandria, VA 22312 


\title{
Computational Study of the Impact of Unsteadiness on the Aerodynamic Performance of a Variable-Speed Power Turbine
}

\author{
Gerard E. Welch \\ National Aeronautics and Space Administration \\ Glenn Research Center \\ Cleveland, Ohio 44130
}

\begin{abstract}
The design-point and off-design performance of an embedded 1.5-stage portion of a variable-speed power turbine (VSPT) was assessed using Reynolds-Averaged Navier-Stokes (RANS) analyses with mixing-planes and sector-periodic, unsteady RANS analyses. The VSPT provides one means by which to effect the nearly 50 percent main-rotor speed change required for the NASA Large Civil Tilt-Rotor (LCTR) application. The change in VSPT shaft-speed during the LCTR mission results in blade-row incidence angle changes of as high as $55^{\circ}$. Negative incidence levels of this magnitude at takeoff operation give rise to a vortical flow structure in the pressure-side cove of a high-turn rotor that transports low-momentum flow toward the casing endwall. The intent of the effort was to assess the impact of unsteadiness of blade-row interaction on the time-mean flow and, specifically, to identify potential departure from the predicted trend of efficiency with shaft-speed change of meanline and 3-D RANS/mixing-plane analyses used for design.
\end{abstract}

\section{Nomenclature}

$A N^{2} \quad$ product of annulus area and shaft-speed squared

$c_{x} \quad$ axial chord

$h_{0}, h \quad$ total and static specific enthalpy

$i, i_{\text {opt }} \quad$ incidence, incidence at minimum loss

$N, N^{*} \quad$ power-turbine shaft speed (rpm), $N / N_{100 \%}$, fraction of $100 \%$ (takeoff) speed

$P R_{T T} \quad$ overall total-pressure ratio

$p_{0}, p \quad$ total and static pressure

$\mathrm{Re}, \mathrm{Re}_{c x} \quad$ Reynolds number, Re based on axial chord

$s$

$T_{0} \quad$ total temperature

$T R_{T T} \quad$ overall total-temperature ratio

$\mathrm{Tu} \quad$ turbulence intensity

$\underline{u} \quad\left(u_{x}, u_{\theta}, u_{r}\right)$, absolute velocity

$U \quad$ rotor speed at pitchline

$Y \quad \frac{p_{0,1}-p_{0,2}}{p_{0,1}-p_{2}}$ loss coefficient

$\alpha, \beta \quad$ absolute and relative flow angles

$\eta_{\mathrm{TT}} \quad$ adiabatic efficiency (total-to-total)

$\rho$ density

$\psi \quad \Delta h_{0} / U^{2}$, work factor

$\varphi \quad u_{\mathrm{x}} / U$, flow coefficient 
Subscripts:

c corrected to standard day

1, 2 blade-row inlet, blade-row exit

4.5 power turbine inlet

\subsection{Introduction}

A key challenge of the NASA Large Civil Tilt-Rotor (LCTR, see Fig. 1) mission is a required variation of main (prop) rotor tip-speed from $650 \mathrm{ft} / \mathrm{s}$ at takeoff to $350 \mathrm{ft} / \mathrm{s}$ at cruise (Ref. 1). The speed variation $\left(54 \%<N / N_{100 \%}<100 \%\right)$, needed to manage main rotor prop efficiency at cruise flight speeds, can be accomplished by utilizing either a two-gear-ratio transmission (Ref. 2) (shifting) with a fixedspeed power-turbine or a variable-speed power turbine (Refs. 3 and 4) (VSPT) with a non-shifting transmission of fixed gear-ratio. A research effort is underway at NASA to address key aerodynamic (Refs. 4 to 7) and rotordynamic (Refs. 7 and 8) challenges of the VSPT approach. Progress related to prediction of the aerodynamic performance of the VSPT as shaft-speed is varied $\left(54 \%<N / N_{100 \%}<100 \%\right)$ is reported herein.

\subsection{Background and Motivation}

Power turbines of turboshaft engines for helicopter applications are typically controlled to a fixed operating speed. While limited speed variation is accommodated in some rotorcraft applications-for example, the AE1107 engine of the V-22 tilt-rotor operates in the range $82 \%<N^{*}<100 \%$ (Ref. 9) - the nearly 50 percent speed power-turbine shaft-speed variation of the NASA LCTR application constitutes an significant departure from the nominal operation of a rotorcraft power turbine. In such operation, incidence angle swings with speed change can be as high as $55^{\circ}$ in the VSPT blade and vane rows.

VSPT conceptual and 3-D aero-designs for the LCTR application conducted recently highlight the need to optimize the turbine design for the required incidence tolerance while achieving cruise efficiency for acceptable fuel burn (Refs. 5 to 9). In the study by NASA (Ref. 5) and Rolls-Royce North American Technologies (Ref. 7), the design-intent air angles were set near the cruise operating VSPT shaft speed $\left(N^{*}=54 \%\right)$ leading to the high $\left(40^{\circ}\right.$ to $\left.55^{\circ}\right)$ negative incidence at takeoff $\left(N^{*}=100 \%\right)$. In the studies of General Electric (Ref. 3) and Williams International (Ref. 6), the optimum design speed was argued to be higher (e.g., $N^{*}=70 \%$ ) than the cruise speed based on a sensitivity study of mission fuel burn versus VSPT design speed. In all cases, the turbines had to operate with acceptable efficiency over an extensive $\left(40^{\circ}\right.$ to $\left.55^{\circ}\right)$ incidence angle range between takeoff (high negative incidence operation) and cruise (less than $5^{\circ}$ to $10^{\circ}$ positive incidence).

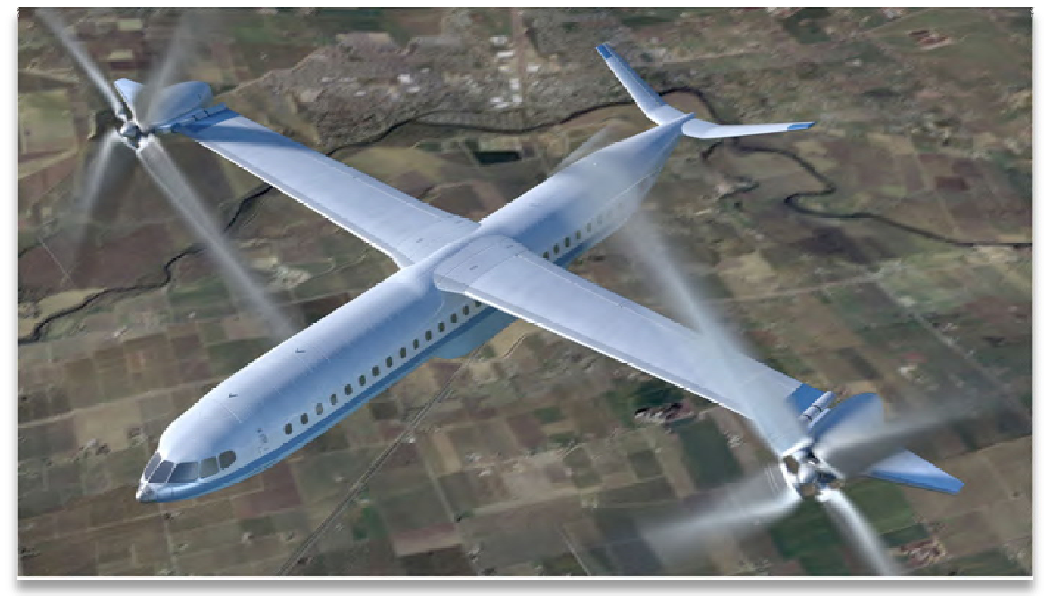

Figure 1.-NASA Large Civil Tilt-Rotor notional vehicle (Ref. 1). 


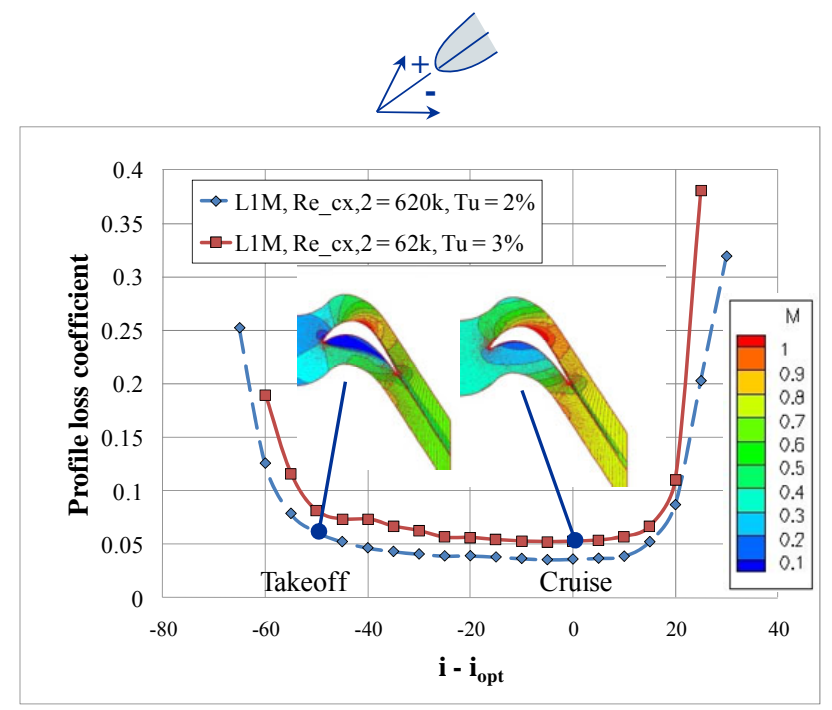

a. 2-D mid-span loss bucket.

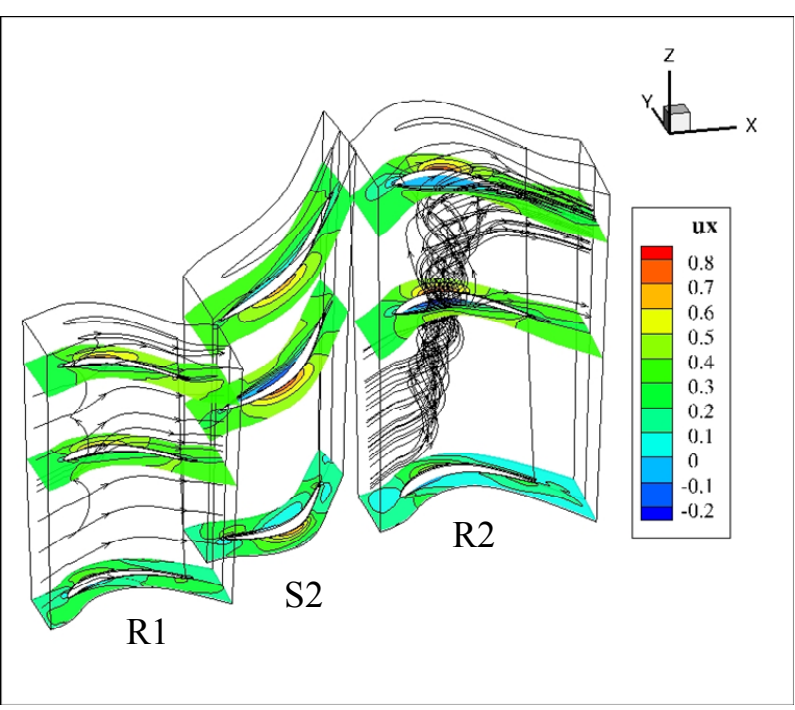

b. Vortical flow structure of pressure-side cove separation admitted in VSPT Rotor 2 at $N^{*}=100 \%$ (takeoff operation).

Figure 2.-(a) Loss bucket for high-lift L1M rotor blading (Ref. 10) showing cruise (design air angles) and takeoff ( $-50^{\circ}$ incidence) operation (Ref. 4); and, (b) vortical flow structure of pressure-side cove separation in Rotor 2 of embedded 1.5-stage of LCTR VSPT at takeoff (Ref. 5).

A computed loss bucket for a 2-D section of representative modern, highly loaded, LPT rotor blading (L1M blading) of Clark (Ref. 10) is shown in Figure 2(a). The 2-D RANS computation (Ref. 4) was conducted using the RVCQ3D (Ref. 11) code with the low-Re $\kappa-\omega$ turbulence model (Ref. 12). The range of the useful incidence (i.e., acceptable loss level) of the highly loaded blade was found to be about $70^{\circ}$ and was typical of LPT blading analyzed in this effort for which the loss buckets collapse well on the canonical off-design loss correlation of Ainley-Mathieson (Ref. 13) (Ref. 4). Note that at negative $55^{\circ}$ incidence, typical of the VSPT incidence levels at LCTR takeoff, the loss levels (Fig. 2(a)) are nearly equal to those of the design air angles (e.g., $0^{\circ}$ incidence) representative of cruise operation. Computed contours of Mach number for $2-\mathrm{D}$ flow fields for cruise $\left(0^{\circ}\right.$ incidence) and takeoff $\left(-50^{\circ}\right.$ incidence) were shown in the insets. A pressure-side cove separation was admitted at the high negative incidence levels of takeoff. Because the separation was closed, and the blade-row was largely unloaded at this condition, the 2-D loss levels associated with this condition were found acceptable. The acceptable loss level at high negative incidence was reflected in the efficiency versus speed trends reported earlier (Refs. 3 to 6) whereby the VSPT efficiency was predicted to be 1.5 to 2 points higher at the unloaded off-design takeoff point $\left(N^{*}=100 \%\right)$ than at the cruise point. There is thus strong impetus for the VSPT designer to set the turbine design speed close to the cruise shaft-speed $\left(N^{*}=54 \%\right)$, and there concentrate aerodynamic design effort on maximizing the VSPT cruise efficiency, while accepting the off-design efficiency levels at the relatively shorter duration takeoff/hover mission points.

The variation of VSPT efficiency with shaft speed was verified at the 3-D RANS mixing-plane level in an earlier study of an embedded 1.5-stages (R1/S2/R2) (Ref. 5). The efficiency-speed trend of RANS/mixing-plane and meanline efficiency levels were found to be the same (Fig. 3). Performance level differences were explained in terms of the 3-D flow effects at design and off-design which are not captured in the meanline loss correlations. In particular, it was noted that the apparent 2-D pressure-side cove separation ( $-50^{\circ}$ in Fig. 2(a)), if admitted in a rotor, was in fact a portion of a large vortical, tornadolike, structure (Rotor 2 in Fig. 2(b)) that transports low-momentum fluid outward in radius toward the outer-span regions along the cove region. This structure was induced by the radial acceleration fields in the rotors acting on the low-momentum cove separation. 


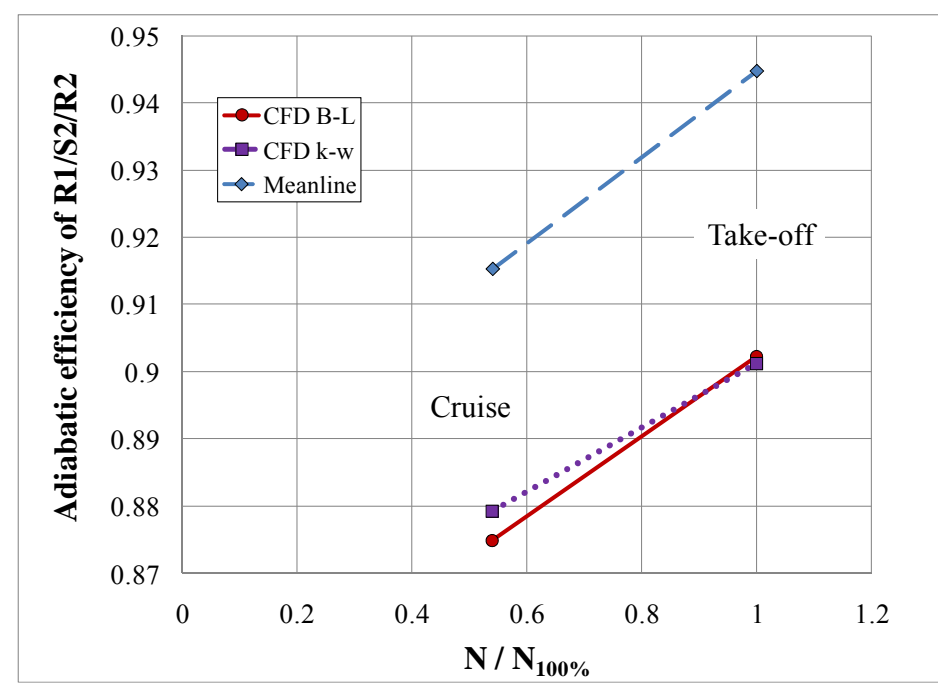

Figure 3.-Variation of embedded 1.5 stage (R1/S2/R2) adiabatic efficiency with speed from cruise $\left(54 \% N^{*}\right)$ to take-off $\left(100 \% N^{*}\right)$, showing comparison between results from 3-D mixing-planes analyses with low-Re $\kappa-\omega$ and fully turbulent Baldwin-Lomax turbulence models with design-intent meanline design/analysis.

The present effort extends the computational analysis from the 3-D RANS/mixing-plane level (Refs. 5 and 6) to 3-D unsteady RANS (URANS) in an effort to assess the influence of unsteadiness associated with blade-row interaction on the design- and off-design aerodynamic performance of a VSPT for the NASA LCTR. The extension is motivated by the potential impact on performance of flow physics not accounted for in mixing-plane analyses. Firstly, a particular concern in the VSPT takeoff conditions is additional entropy production associated with the unsteady forcing of the vortical structure (Fig. 2(b)) in the pressure-side cove, which might degrade VSPT efficiency levels and modify the efficiency-speed trend relative to the meanline and steady 3-D RANS/mixing-plane used in the turbine design process. The unsteady computations will simulate, to some degree of accuracy, the influence of blade-row interaction associated with potential fields and wakes (and pitchwise nonuniformity) passing between multistage blade rows. In regions of vortical flow-for example, in the pressure-side cove region of rotors at high negative incidence (Fig. 2(b)) - periodic unsteadiness associated with blade row interaction will lead to deterministic stress (Ref. 14) and heat flux fields that redistribute momentum and energy in the time-mean flow field. Secondly, the unsteady computations eliminate the need for the mixing-plane between blade rows, and accommodate transport of streamwise vorticity to/from blade rows, thereby admitting proper influence of vorticity associated with secondary flow field of one blade row on the instantaneous and time-mean flow fields of downstream blade rows (Ref. 14). Thirdly, the unsteady computations simulate spatiotemporal loss production associated with wake transport and stretching (Ref. 15) to some degree of accuracy (grid dependent). Lastly, Haselbach et al. (Ref. 16) and others have highlighted the impact of vortical unsteadiness in wakes from upstream blade rows on the design-point loss levels of transitional, low-Re LPT blade rows. The interaction of a passing wake with a transitional LPT boundary-layer at lowRe conditions has been studied in great detail (Ref. 17). At a given aerodynamic loading level, the loss levels in steady flows were found to be substantially (e.g., 20 percent) higher than when subjected to wake passing; further, the loss increase with Reynolds number lapse (sensitivity) was mitigated to some degree (Ref. 16). The impact of wake vorticity on the transitional blade and endwall flows was beyond the scope of the low-Re $\kappa-\omega$ turbulence models used in the present study work (Ref. 18). 


\subsection{Approach}

As in earlier mixing-plane analyses (Ref. 5), an embedded 1.5-stage (R1/S2/R2) of a 4-stage VSPT (Fig. 4) for the LCTR application was considered in the present study. The intent of the 3-D design was to create a representative embedded 1.5 stage $(\mathrm{R} 1 / \mathrm{S} 2 / \mathrm{R} 2)$ with design-point stage efficiencies consistent with the meanline, in which the impact of off-design operation of a rotor impacts the off-design performance of a stator (R1/S2), and vice-versa (S2/R2). Stator 1 (S1) was not included in the simulations because the S1 inlet and exit flow angles would not change appreciably with speed change; therefore, the $\mathrm{S} 1$ design was assumed achievable, and the $\mathrm{S} 1$ exit conditions at design and off-design exit flow conditions were set to those of the meanline analyses. For the case of the URANS simulations herein, the impact of the unsteadiness and streamwise vorticity of the S1 secondary flow field transported from S1 to $\mathrm{R} 1$, and subsequently through the 1.5-stage, was evidently neglected. Stage 2 stator (S2) was the first embedded blade row of the simulation, and R2 was the first rotor with forcing from an upstream stage (R1/S2). The impact the influence of the downstream stator row, S3, on the R2 flow field was neglected in the present study.

The assessment of the impact of unsteadiness due to blade-row interaction documented in this paper relied on results from RANS/mixing-plane and sector-periodic URANS simulations conducted using a commercial code (described below); therefore, a portion of the effort was first concentrated on verifying that the mixing-plane solutions obtain the commercial software were in qualitative agreementparticularly with respect to flow field structures and the trend of efficiency with speed change-with results from a validated in-house NASA code used in the earlier VSPT mixing-plane analysis (Ref. 5) before embarking on the URANS analyses.

The paper is organized in the following manner. The VSPT operating requirements and conceptual and 3-D blade design approaches are reviewed. Results from a NASA in-house RANS/mixing-plane solver are then compared to steady and time-averaged, average-passage results from a commercially available code with both RANS/mixing-plane and sector-periodic URANS capabilities. Conclusions regarding the impact of unsteadiness on VSPT efficiency and the trend of efficiency with shaft-speed change are then provided.

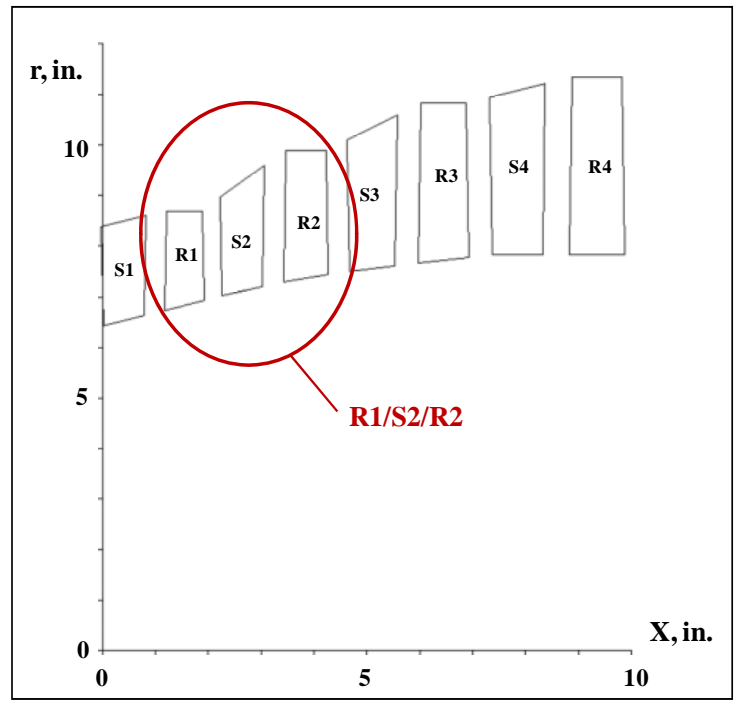

Figure 4.-Four-stage VSPT flow path from meanline design code, showing embedded 1.5-stage of computational analysis (Ref. 5). 


\subsection{VSPT Requirements and Aerodynamic Design}

\subsection{Turbine Requirements}

The NASA LCTR notional vehicle (Fig. 1) is envisaged to be a 90 passenger aircraft with $100,000 \mathrm{lb}_{\mathrm{f}}$ takeoff gross weight. There are two engines per nacelle (and main rotor), currently conceived to be of the 7,500 shp-class level. Two key LCTR mission points are 2,000 ft takeoff/hover and 28,000 ft, Mach 0.5 cruise. At takeoff, the main rotor and VSPT operate at $100 \% N^{*}$, while at cruise the rotors and VSPT are slowed to $54 \% N^{*}$. Specific VSPT requirements of an LCTR engine cycle study (Ref. 19) were provided in Table 1.

\subsection{Conceptual Design}

The conceptual and 3-D aero-design approach for a 4-stage VPST of the LCTR application was described in detail earlier (Ref. 5). The design air-angles were set at the cruise operating condition (54 percent $\left.N^{*}\right)$ where Reynolds numbers were lowest and work factors $\left(\Delta h_{0} / U^{2}\right)$ were highest. The VSPT flow path from the free-vortex meanline ${ }^{1}$ analysis was provided in Figure 4. Key turbine parameters, including blade row incidence levels at off-design, were provided in Table 2, and the design flow angles, some (see R2) with turning as high as $110^{\circ}$, were provided in Table 3.

\begin{tabular}{lcc} 
TABLE 1._-VSPT REQUIREMENTS AT KEY FLIGHT \\
\multicolumn{3}{c}{ POINTS OF LCTR MISSION (REF. 5) } \\
\hline Flight point & Takeoff & Cruise \\
Altitude & $2 \mathrm{k}-\mathrm{ft}$ & $28 \mathrm{k}-\mathrm{ft}$ \\
VSPT shaft-speed $\left(N / N_{100 \%}\right)$ & $100 \%$ & $54 \%$ \\
Main-rotor tip-speed & $650 \mathrm{ft} / \mathrm{s}$ & $350 \mathrm{ft} / \mathrm{s}$ \\
\hline Power, SHP & 4593 & 2328 \\
Mass flow rate, $\mathrm{lb}_{\mathrm{m}} / \mathrm{s}$ & 22.03 & 12.22 \\
Specific power $\left(\mathrm{BTU} / \mathrm{lb}_{\mathrm{m}}\right)$ & 147 & 135 \\
Inlet temperature $\left(T_{0,4.5}\right), \mathrm{R}$ & 2204 & 1812 \\
Inlet pressure $\left(p_{0,4.5}\right), \mathrm{psia}$ & 58.0 & 26.76 \\
$P R_{\mathrm{TT}}$ & 4.04 & 5.34 \\
Corrected flow, $\mathrm{lb}_{\mathrm{m}} / \mathrm{s}$ & 11.51 & 12.54 \\
Corrected speed $\left(N_{\mathrm{c}} / N_{\mathrm{c}, 100 \%}\right), \%$ & 102.3 & 60.8 \\
Aft-stage unit-Re $\left(\right.$ in. $\left.{ }^{-1}\right) *$ & $50,000 /$ in. & $30,000 /$ in. \\
\hline
\end{tabular}

${ }^{\mathrm{a}}$ Based on static conditions at last stage rotor with exit relative Mach number of 0.7 .

TABLE 2.-FOUR-STAGE DESIGN FOR LCTR VSPT REQUIREMENTS OF TABLE 1 (REF. 5)

\begin{tabular}{lcc}
\hline & Takeoff & Cruise \\
\hline Speed $\left(\boldsymbol{N} / \boldsymbol{N}_{\mathbf{1 0 0} \%}\right)$ & $\mathbf{1 0 0 \%}$ & $\mathbf{5 4 \%}$ \\
\hline VSPT efficiency & 0.9294 & 0.9154 \\
$P R_{\mathrm{TT}}$ & 4.04 & 5.34 \\
$N$, rpm & 15,000 & 8,100 \\
Average $\psi$ & 0.75 & 2.36 \\
Average $\phi$ & 0.493 & 0.957 \\
Average $\Delta h_{0}, \mathrm{BTU} / \mathrm{lb}_{\mathrm{m}}$ & 41.8 & 39.1 \\
Max. $A N^{2}, \mathrm{rpm}^{2} \cdot \mathrm{in}^{2}$ & $47.7 \times 10^{9}$ & $13.9 \times 10^{9}$ \\
Stage efficiency & $0.9371,0.9219$, & $0.9105,0.8887$, \\
$($ Stg $1,2,3,4)$ & $0.9229,0.9068$ & $0.9050,0.9251$ \\
Rotor incidence, deg. & $-38,-42$, & 0 \\
(R1, R2, R3, R4) & $-50,-54$ & 0 \\
Stator incidence, deg & $-34,-40$, & 0 \\
$(\mathrm{~S} 2, \mathrm{~S} 3, \mathrm{~S} 4, \mathrm{EGV})$ & $-48,-35$ & \\
\hline
\end{tabular}
${ }^{1}$ The Turbine Design and Analysis System (Ref. 10) of Dr. J.P. Clark, AFRL, includes design and off-
design meanline codes and blade profile generator of F. Huber, Florida Turbine Technologies, Inc. 


\begin{tabular}{cccc|ccc}
\multicolumn{6}{c}{ TABLE 3.-DESIGN-POINT AIR ANGLES OF } \\
\multicolumn{4}{c}{ 4-STAGE VSPT $\left(A N^{2}=47.7\right.$} & $10^{9} \mathrm{rpm}^{2} \cdot$ in. $\left.^{2}\right)($ REF. 5) \\
\hline Stage & \multicolumn{3}{c}{ Stator vane } & \multicolumn{3}{c}{ Rotor blade } \\
\hline & $\boldsymbol{\alpha}_{1}$ & $\boldsymbol{\alpha}_{2}$ & Turn & $\beta_{1}$ & $\boldsymbol{\beta}_{2}$ & Turn \\
$\mathbf{1}$ & 0 & 62 & 62 & 42 & -56 & 99 \\
$\mathbf{2}$ & -39 & 64 & 104 & 50 & -60 & 110 \\
$\mathbf{3}$ & -42 & 62 & 104 & 42 & -56 & 98 \\
$\mathbf{4}$ & -31 & 54 & 85 & 27 & -47 & 74 \\
\hline
\end{tabular}

\subsection{3-D Aerodynamic Blade Design of Embedded 1.5-Stage}

The 3-D aero-design of the blading for the 1.5-stage (R1/S2/R2) of the present study was described in detail earlier (Ref. 5). R1 and R2 were shrouded, and leakage flows were neglected. With design air angles from the meanline design code, the AFRL Turbine Design and Analysis System (TDAAS (Ref. 10)) was used to design, optimize, and stack 2-D airfoil sections, at hub, mid-span, and tip, into a 3-D blade geometry. The chordwise-location of maximum loading was influenced by the findings of Gier et al. (Ref. 20) concerning efficiency, Re-lapse, and sensitivity to incidence in low pressure turbines designed for low-Re operation. The 2-D sections (provided in Ref. 5) were stacked on their center of gravity along a radial stacking axis. No dihedral was considered in the present study, although the benefits of 3-D aerodynamic design (Ref. 21) might well prove of benefit in managing the secondary flow fields discussed in Section 4.0.

\subsection{Computational Tools}

\subsection{SWIFT 3-D RANS/Mixing-Plane Solver}

In the previous study (Ref. 5), design- and off-design conditions were analyzed using the 3-D RANS turbomachinery flow solver, SWIFT (Ref. 22). The finite-difference form of the thin-layer Navier-Stokes equations in Cartesian coordinates were marched with local time-stepping using a multi-stage explicit Runge-Kutta integration with implicit residual smoothing. Inviscid flux vector differences were calculated using central-differencing with artificial dissipation, or with the H-CUSP (used herein) or AUSM ${ }^{+}$ upwind schemes. The viscous terms were central differenced. 3-D C-grids without clearance blocks were used in all blade rows and were generated using the TCGRID code (Ref. 23). The fully turbulent variant of the Baldwin-Lomax (Ref. 24) (B-L) and Wilcox's low-Re $\kappa-\omega$ turbulence model for transitional flows (Ref. 12) were used. The results from the low-Re $\kappa-\omega$ turbulence model were considered in the present study. The SWIFT code has been validated against a number of turbomachinery data sets (Ref. 25).

The mixing-plane interface condition was used between blade rows in RANS/mixing-plane computations (SWIFT and LEO below). In addition to neglecting unsteady blade-row interaction, the mixing-plane approach does not conserve streamwise vorticity between blade rows. The mixing-plane assumption was, therefore, expected to degrade accuracy at high load (design) and off-design conditions with attendant strong secondary flow fields and blade-row interaction levels.

\subsection{LEO 3-D RANS/Mixing-Plane and URANS Solver}

The WAND grid generator and LEO RANS/URANS flow solver of AeroDynamic Solutions, Inc (ADS) were used for both 3-D RANS/mixing-plane and URANS computations (Ref. 26). The ADS software was selected for the URANS analyses because it was available to the author due to its utilization by the AFRL design system (TDAAS). The WAND code was used to generate structured grids (O-H-H-H multi-blocks) suitable for turbulent flow with integration to the wall (near-wall $\mathrm{y}^{+}$near unity). No clearance blocks were used. LEO was used for both 3-D RANS single-passage, multistage, mixing-plane calculations; and, 3-D, time-accurate, sector-periodic URANS computations with sliding interfaces between blade rows. The Navier-Stokes equations, in finite-volume form and in cylindrical coordinates, 
were marched in time: local time stepping and multi-grid were used for the mixing-plane computations; and, implicit dual-time-stepping (Ref. 27) was used for time-accurate simulations. The LEO code is density based. Flux vectors were discretized using central-differencing with artificial dissipation. The low-Re $\kappa-\omega$ turbulence model (Ref. 12) was used.

The multistage LEO/URANS computations of the present study utilized an implicit scaling ${ }^{2}$ algorithm to set flux vectors at the sliding interfaces. The implicit scaling algorithm allows arbitrary blade counts (e.g., 87/73/81 for R1/S2/R2 of the LCTR VSPT) to be approximated by specified reduced-count periodic sectors (e.g., 9/7/8 herein) for the sake of computational efficiency. The blade geometry of the baseline turbine was not modified; rather, for each blade row, the physical $\theta$-extent swept-out by the periodic sector of the reduced blade-count description, was mapped to a nondimensional unit extent. The scaling factors for this unit mapping were subsequently used at each time-step to establish the interpolation appropriate to the baseline physical geometry, given the interpolation effected at the interface of the nondimensional periodic sectors of extent unity.

After converging the URANS simulations to time-periodicity, the time-averaged flow field in each passage of the simulation was obtained by an arithmetic average (for constant time steps) of the q-vectors at each node over a user specified number of time-steps (1350 time steps herein, corresponding to rotor traverse of the periodic sector); similarly, attainment of an average passage in each blade row was accomplished by obtaining an arithmetic average of the time-averaged q-vectors at each node over the number of passages in the periodic sectors of that blade row. The time- and average-passage averaging were accomplished by using utilities available from ADS.

\subsection{Grid Topologies}

The SWIFT computations were conducted using a C-grid generated using the TCGRID (Ref. 23) code while the LEO solver utilized an O-H-H-H grid (no clearance block) generated using the WAND (Ref. 26) code. The grids for R1 are shown in Figure 5. The SWIFT grids (Fig. 5(a)) have $565 \mathrm{k}$ grid cells per blade while the LEO grids have approximately $665 \mathrm{k}$ grid cells per blade. The LEO grid was purposely generated using the ADS recommended WAND input values for fine turbomachinery grids.

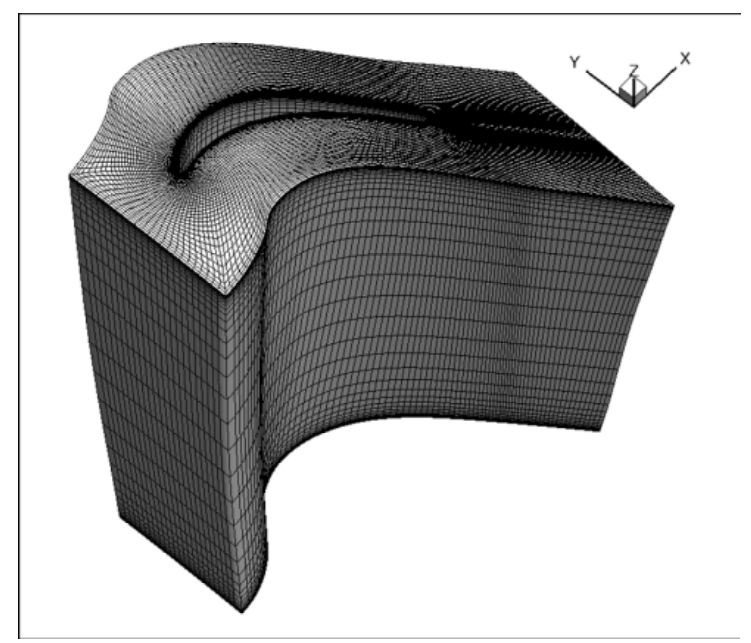

a. C-grid from TCGRID

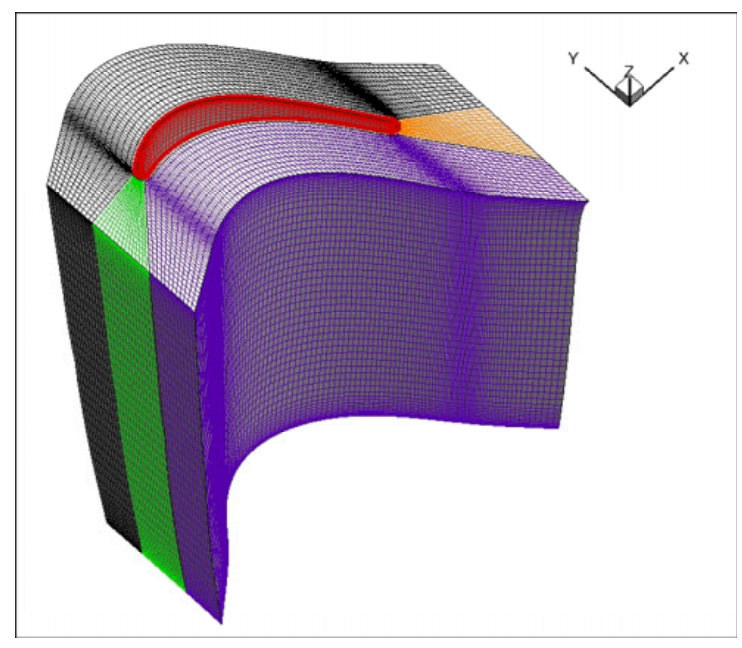

b. O-H-H-H grid from WAND

Figure 5.-Rotor 1 grids used in RANS/mixing-plane and URANS computations.

\footnotetext{
${ }^{2}$ Summarized in an unpublished write-up, Ni, R-H, Ni, M., and Fan, G., "Unsteady Analysis of a Multi Stage Axial Turbine Using Implicit Scaling," May, 2011.
} 


\subsection{Boundary Conditions}

Boundary conditions were obtained from the design and off-design meanline analyses. Inlet total conditions and swirl angles at mid-span were prescribed along with an assumption of free-vortex flow. The free vortex flow is consistent with the spanwise flow distributions of the meanline code and the 2-D airfoil design. Radial equilibrium, with a prescribed static pressure (at hub for SWIFT and mid-span for LEO) was enforced at the exit boundary.

\subsection{RANS/Mixing-Plane Results and Comparison}

Comparisons of the RANS/mixing-plane results of SWIFT and LEO, for the embedded 1.5-stage turbine (R1/S2/R2) at the design $\left(54 \% N^{*}, 28 \mathrm{k}\right.$-ft cruise) and off-design (100\% $N^{*}, 2 \mathrm{k}$-ft take-off) conditions, are presented in this section. First computed design and off-design spanwise profiles are compared to meanline predictions. At both design $\left(54 \% N^{*}\right)$ and off-design $\left(100 \% N^{*}\right)$, the 3-D structures associated with secondary flow transport and rotor acceleration fields are then discussed. Comparison of design- and off-design performance levels at the blade row, stage, and overall 1.5-stage performance levels is deferred to Section 6.0.

\subsection{Spanwise Profiles}

Spanwise profiles of pitchwise-averaged (mixed-out) normalized total-temperature and total-pressure (referenced to S1 inlet conditions) and absolute flow angles were provided below (Figs. 6 to 8) for the design-point (cruise, $N^{*}=54 \%$ ) and off-design (takeoff, $N^{*}=100 \%$ ) conditions. The computed R1 inlet total-temperature is unity (not plotted in Fig. 6), as specified by the meanline analysis. The inlet boundary-layer thickness is evident in the R1 inlet total-pressure profile (black) in Figure 7. The R1-inlet absolute flow angles computed using both the SWIFT and LEO codes absolute flow matched the freevortex profile of the meanline (black) shown in Figure 8.

In general, the agreement between the RANS/mixing-plane solver (SWIFT and LEO) and the meanline tool for total-temperature (Fig. 6), an indication of work, and total-pressure (Fig. 7) were acceptable, with the exception of the LEO mixing-plane results near the casing endwall, where nonphysical $T_{0}$ distributions were evident. After investigation, it was noted that the region of non-physical $T_{0}$ (negative entropy) was introduced by the LEO mixing-plane algorithm at spanwise sections containing negative axial velocity at the mixing-plane. Resolution of the issue associated with reverse-flow at the LEO mixing plane remains for future work.

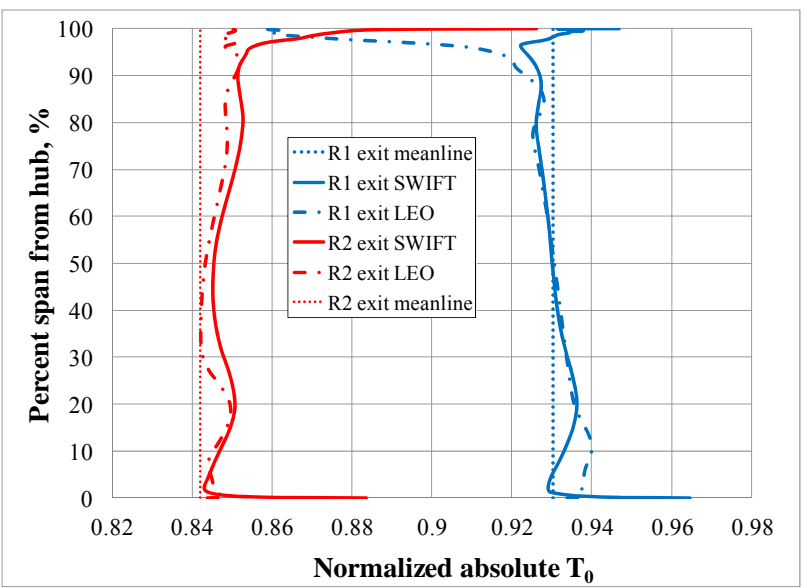

a. Design-point (cruise, $N^{*}=54 \%$ )

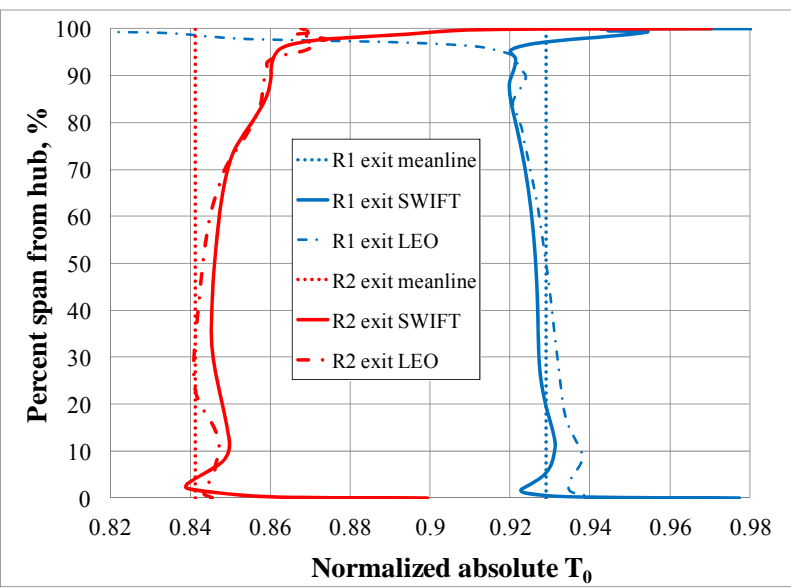

b. Off-design (takeoff, $N^{*}=100 \%$ )

Figure 6.-Spanwise profiles of normalized total-temperature, $T_{0}$, at R1 and R2 exits, showing comparison with meanline at design point (54\% $N^{*}, 28 \mathrm{k}$-ft cruise) and off-design (100\% $N^{\star}, 2 \mathrm{k}$-ft takeoff). 


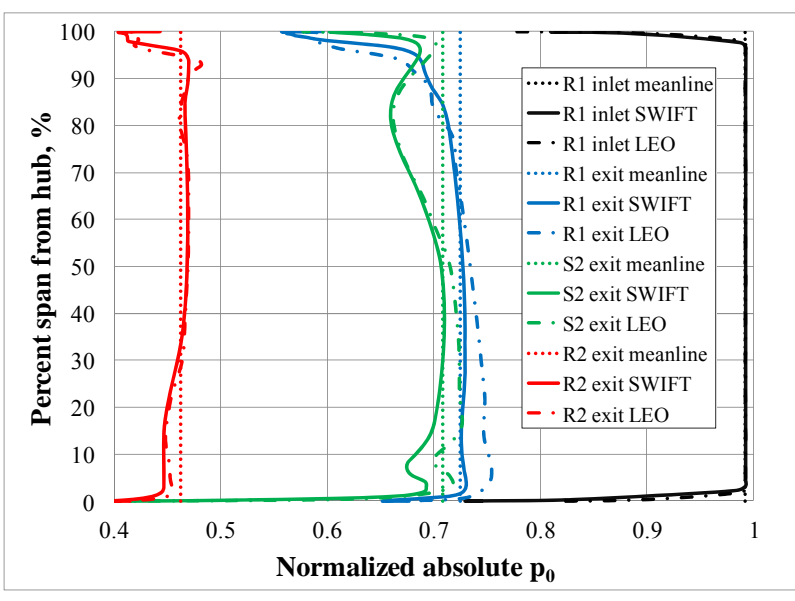

a. Design-point (cruise, $N^{*}=54 \%$ )

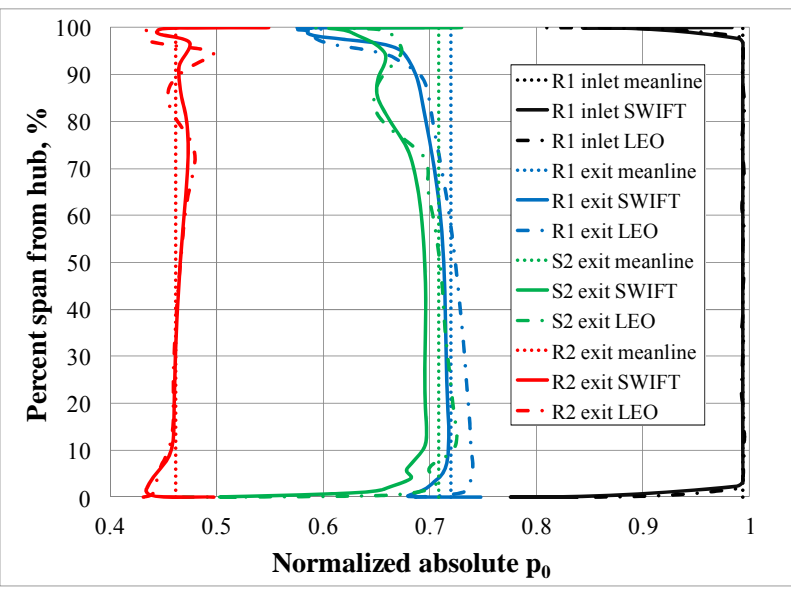

b. Off-design (takeoff, $N^{*}=100 \%$ )

Figure 7.-Spanwise profiles of normalized total-pressure, $p_{0}$, at R1 inlet and R1, S2, and R2 exits, showing comparison with meanline at design point (54\% $N^{*}, 28 \mathrm{k}$-ft cruise) and off-design (100\% $N^{*}, 2 \mathrm{k}$-ft takeoff).

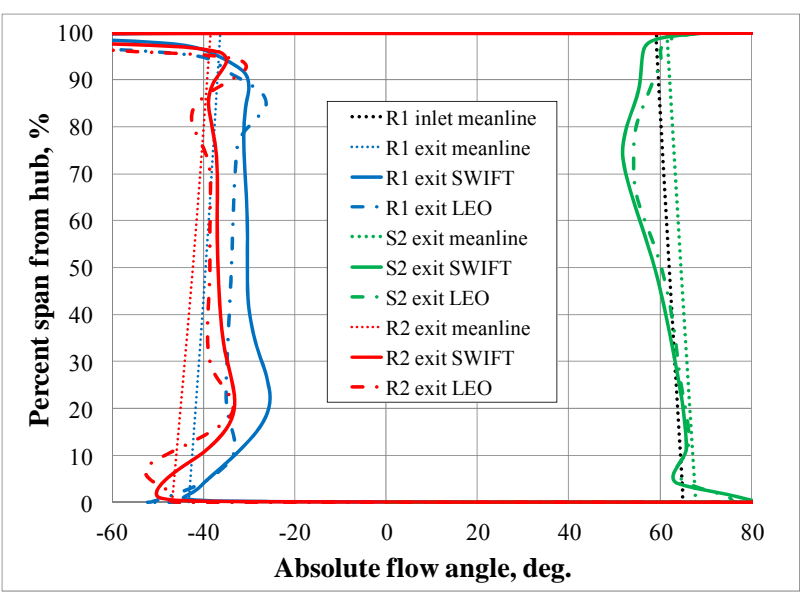

a. Design-point (cruise, $N^{*}=54 \%$ )

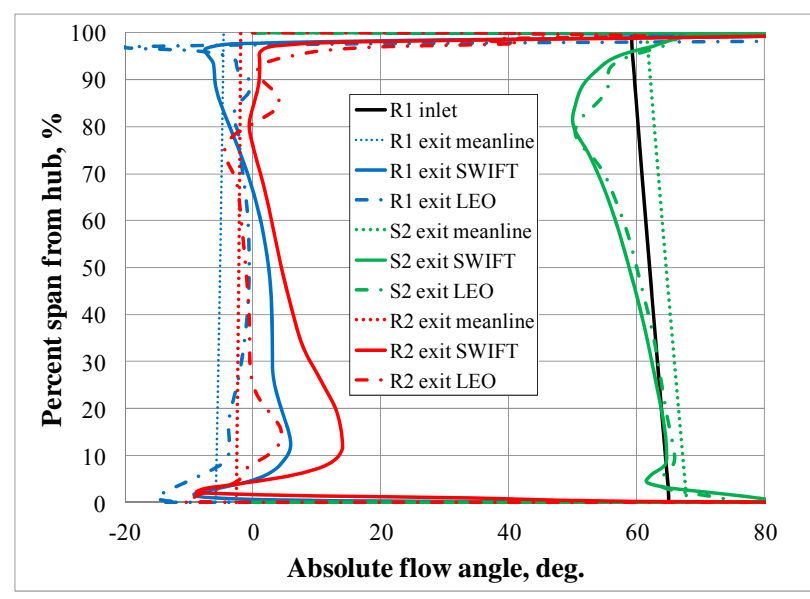

b. Off-design (takeoff, $N^{*}=100 \%$ )

Figure 8.-Spanwise profiles of absolute flow angle at R1 inlet and R1, S2, and R2 exits, showing comparison with meanline at design point (54\% $N^{*}, 28 \mathrm{k}$-ft cruise) and off-design (100\% $N^{\star}, 2 \mathrm{k}$-ft takeoff).

For the design- and off-design conditions, both solvers predicted a deficit in pitchwise-averaged totalpressure at the exit of S2 (from 60 to 95 percent of span at design and 70 to 95 percent at off-design). The $\mathrm{R} 2$ discharge was weak from hub to 20 percent of span at design. The magnitude and spanwise-location of the $p_{0}$-deficits were consistent with the cross-passage contours of entropy shown in Figures 9 and 10. Low enthalpy extraction (Fig. 6 and turning Fig. 8) was predicted by both solvers for the prescribed pressure ratio (Fig. 7), though LEO was generally closer to design-intent (meanline). The axial rating planes for the CFD and meanline were not coincident, which might have contributed to the disparity in CFD and meanline flow angles (Fig. 8). In general, the LEO and SWIFT flow angles tracked one another qualitatively, though inflection points in the R1 and R2 exit profiles (e.g., Fig. 8) were shifted spanwise relative to each other, indicating differences in the transport of low momentum flow by the secondary flow fields. 


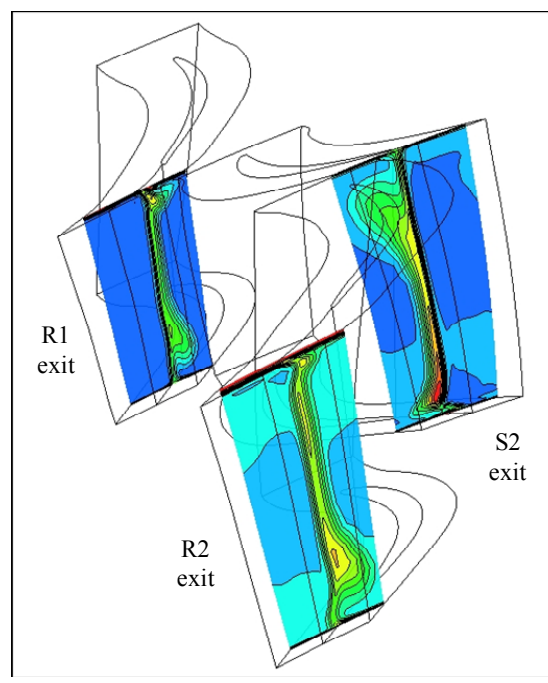

a. SWIFT

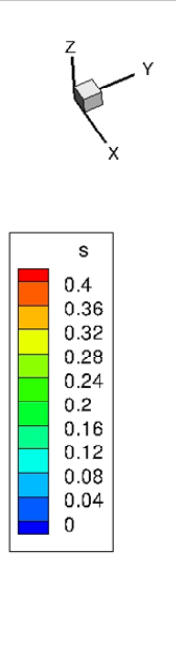

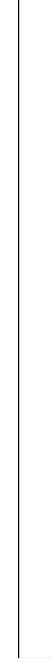

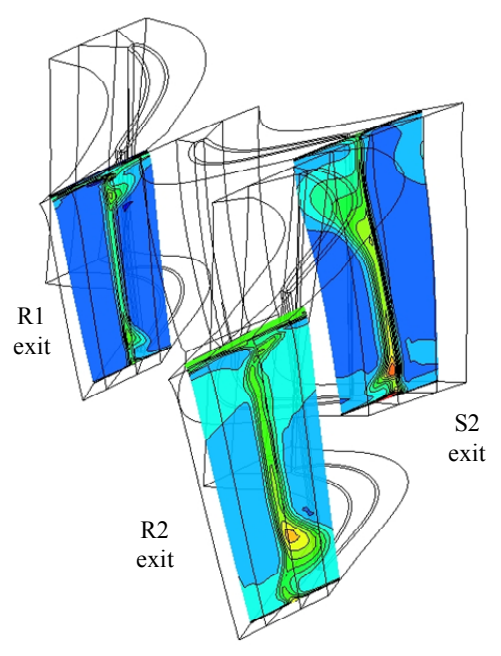

b. LEO

Figure 9.-Computed contours of entropy at the blade-row exit planes from RANS/mixing-plane calculations at design point $\left(54 \% N^{\star}, 28 \mathrm{k}\right.$-ft cruise).

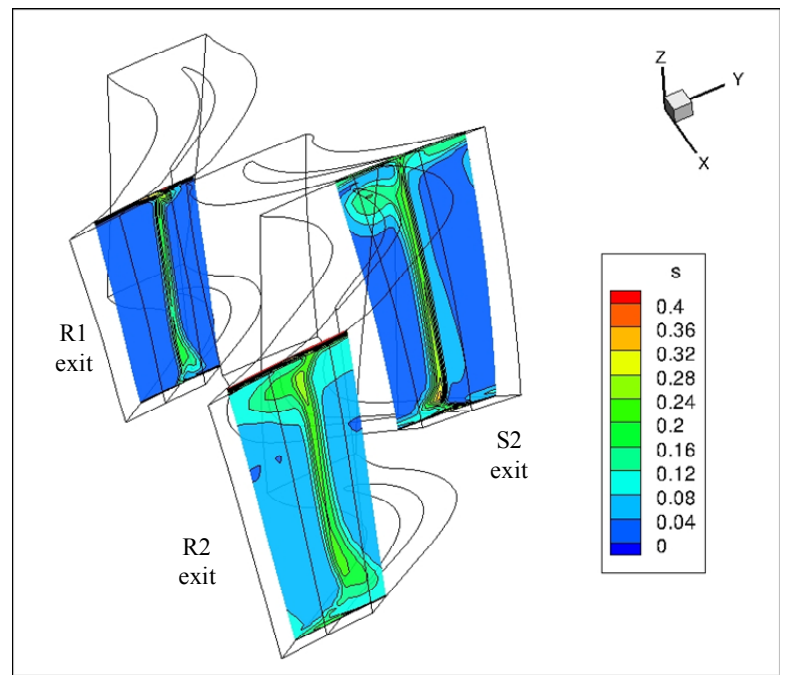

a. SWIFT

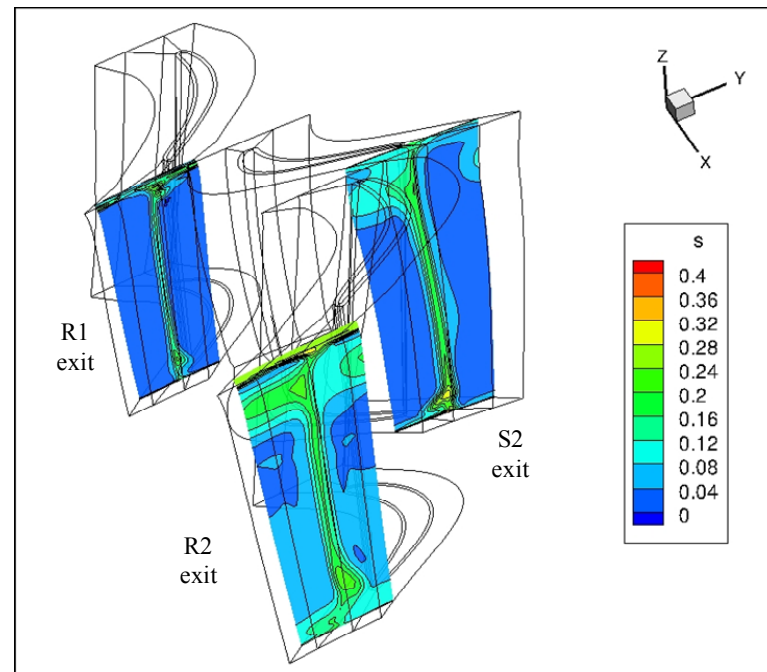

b. LEO

Figure 10.-Computed contours of entropy at the blade-row exit planes from RANS/mixing-plane calculations at off-design point (100\% $N^{\star}, 2 \mathrm{k}$-ft takeoff).

\subsection{Cross-Passage Contours at Blade-Row Exits}

\subsubsection{Design-Point ( $28 \mathrm{k-ft}, 54 \% \mathrm{~N}^{*}$ )}

Design-point ( $28 \mathrm{k}-\mathrm{ft}, 54 \% N^{*}$ ) entropy contours at the exit plane of blade rows R1, S2, and R2, computed using SWIFT and LEO RANS/mixing-plane, were provided in Figure 9. The low momentum flow, transported by the secondary flow field, accumulated preferentially at the hub/suction-side corners of the rotors and at the case/suction-side corner of the stator. With the mixing-plane approximation, these regions of low relative total-pressure were mixed-out between blade rows, and were manifested as axisymmetric bands (not shown) of high entropy flow downstream of each mixing plane. In practice, the regions of high aerodynamic-blockage would be strong sources of unsteadiness and induce spanwise mixing in the downstream blade row. In general, the contours from the RANS/mixing-plane calculations - SWIFT and LEO — were in good agreement. 


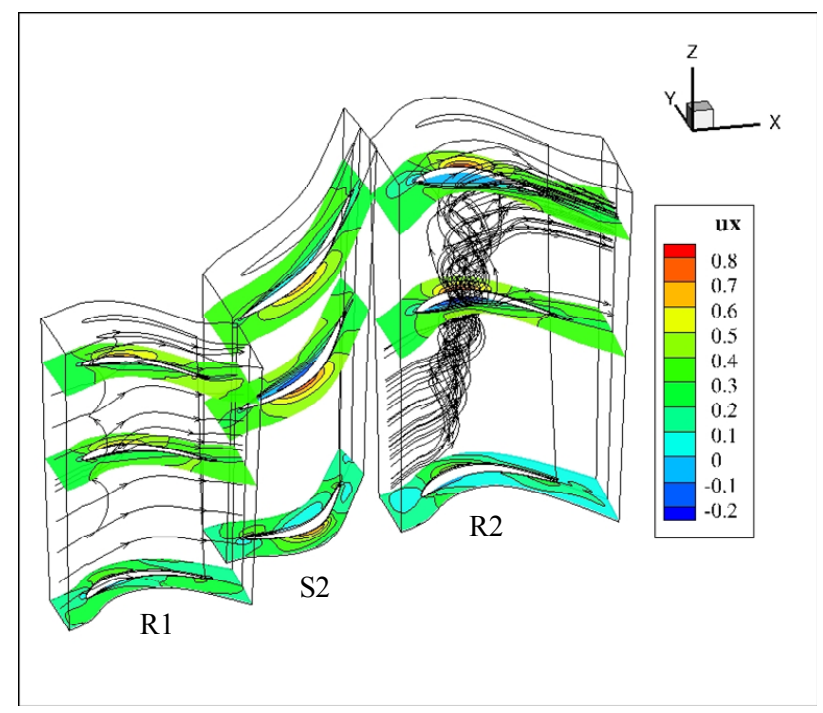

a. SWIFT

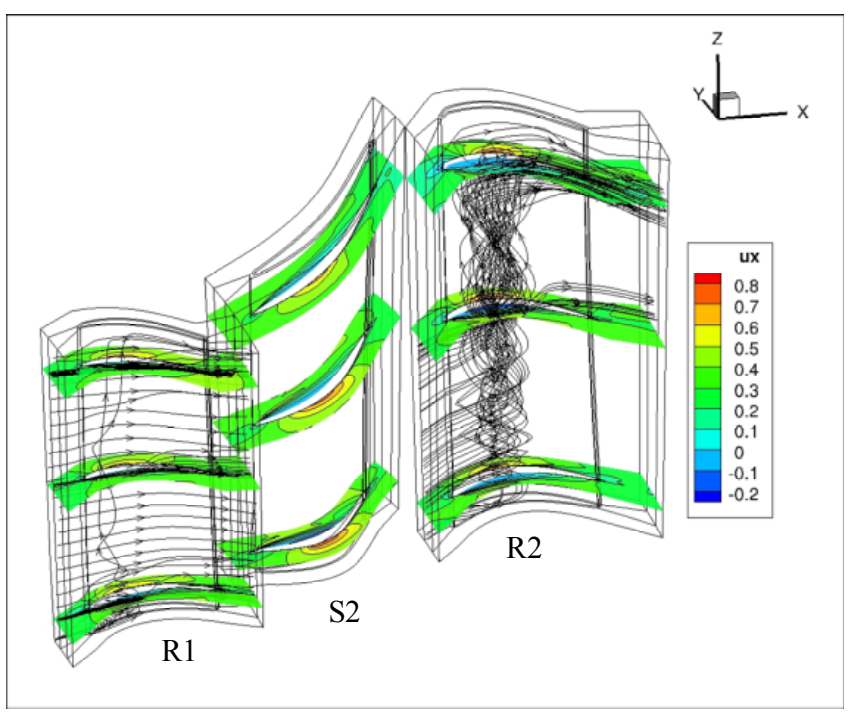

b. LEO

Figure 11.-Contours of axial velocity and streamlines in R1 and R2 at the $100 \% N^{\star}$ off-design takeoff point from mixing-plane computations of (a) SWIFT (Ref. 5) and (b) LEO.

\subsubsection{Off-Design ( $\left.2 \mathrm{k}-\mathrm{ft}, 100 \% N^{*}\right)$}

The off-design ( $2 \mathrm{k}-\mathrm{ft}, 100 \% N^{*}$ ) entropy contours at the exit plane of blade rows R1, S2, and R2 were provided in Figure 10. Again, the two RANS/mixing-plane solvers were in good agreement. As at the design point (Fig. 9), the secondary flow fields transported flow to the rotor hub/suction-side corners and stator case/suction-side corner. Compared to the design-point flow, the regions of lower total-pressure were more diffuse, particularly in the high-turning second rotor, R2, due to the redistribution of low momentum flow from the hub regions to the casing via the pressure-side cove separation/vortex (Fig. 11).

As shown in Figure 11, both RANS/mixing-plane solvers showed little reverse flow in the pressureside cove region of R1 at the off-design (negative incidence) condition. In R2, the strong vortical structure in the pressure-side cove was predicted by both solvers. The low-momentum flow was transported radially outward and discharged from the rotor at about 75 percent of span from hub. S2 had significant regions of reverse flow in the pressure-side cove as well at the off-design point; however, without the strong radial acceleration fields, no comparable 3-D structure was formed in the stator.

\subsection{URANS Comparison With RANS/Mixing-Plane}

As noted in the previous section, the results from the SWIFT and LEO RANS/mixing-plane solvers agreed well. In this section, the LEO RANS/mixing-plane results were compared with time-averaged, averaged-passage results from LEO sector-periodic URANS simulations at the VSPT design- and offdesign operating conditions.

\subsection{Spanwise Profiles}

Neglecting differences in the R1 exit profile (Fig. 12) in the first 5 percent immersion from case (associated with the LEO mixing-plane issue described earlier), the time-averaged, averaged-passage URANS results were in substantial agreement with the mixing-plane results. R1 and S2 exit profiles of $T_{0}$ (Fig. 12) and $p_{0}$ (Fig. 13) reflected negligible impact of unsteadiness in R1 and S2. Differences were noted in the R2-exit temperature profile (Fig. 12) where the greatest impact of unsteadiness associated with blade rows R1 and S2 was anticipated. At design-point operation the URANS $T_{0}$ and $p_{0}$ distributions (Figs. 12(a) and 13(a)) reflected lower R2 work extraction (and efficiency) from 0 to 60 percent span 
from hub. At the extreme negative incidence point of off-design operation, the unsteadiness due to bladerow interaction was most expected to impact the time-mean flow in the pressure-side cove. The R2 work (Fig. 12(b)) of the URANS simulation was lower at 75 percent span from hub, perhaps reflecting the impact of unsteadiness on the tornado structure discharged at about this spanwise location (Fig. 11).

\subsection{Cross-Passage Contours at Blade-Row Exits}

Consistent with the agreement in the spanwise distributions, RANS/mixing-plane and URANS timeaveraged, average passage (URANS TA/AP) results for the design- (Fig. 15) and off-design (Fig. 16) operating points agreed well. The URANS TA/AP results are generally more diffuse than the mixingplane, reflective of the spatial envelope of time-dependent motion of vortical structures; nonetheless, the RANS/mixing plane results have evidently captured the key blade row flow physics quite well, in spite of the recognized modeling limitations introduced by the mixing-plane assumption (Section 1.1). The offdesign results (Fig. 16), at which the blade-rows were most unloaded (low turning) and negativeincidence levels into all blade rows were highest, were in particularly good agreement.

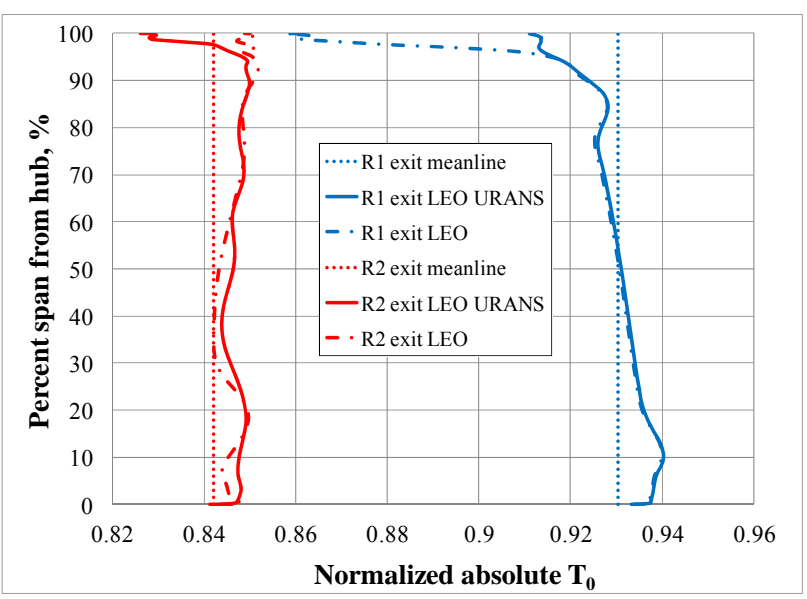

a. Design-point (cruise, $N^{*}=54 \%$ )

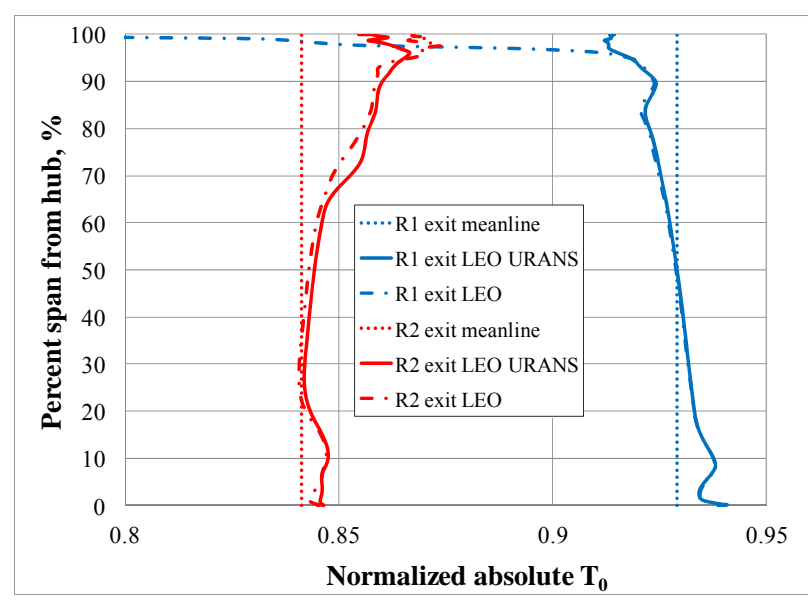

b. Off-design (takeoff, $N^{*}=100 \%$ )

Figure 12.-Spanwise profiles of normalized total-temperature, $T_{0}$, at R1 and R2 exits, showing comparison with meanline at design point (54\% $N^{*}, 28 \mathrm{k}$-ft cruise) and off-design (100\% $N^{*}, 2 \mathrm{k}$-ft takeoff).

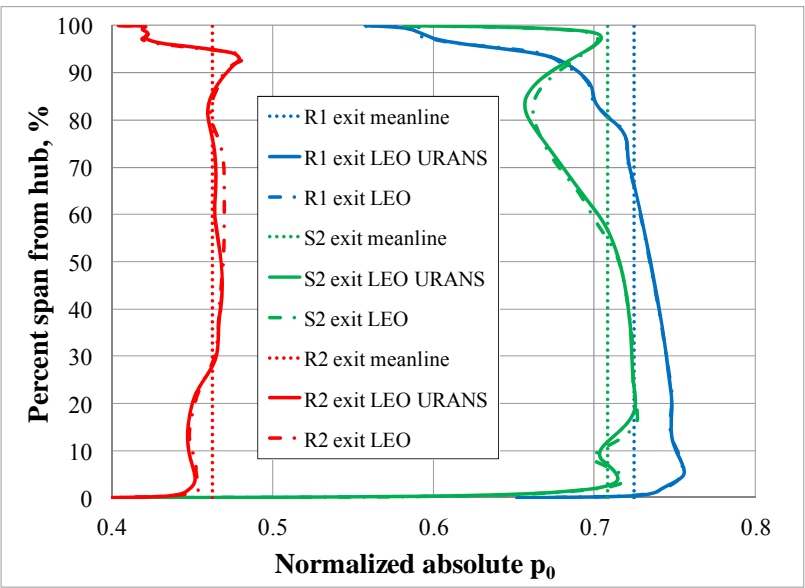

a. Design-point (cruise, $N^{*}=54 \%$ )

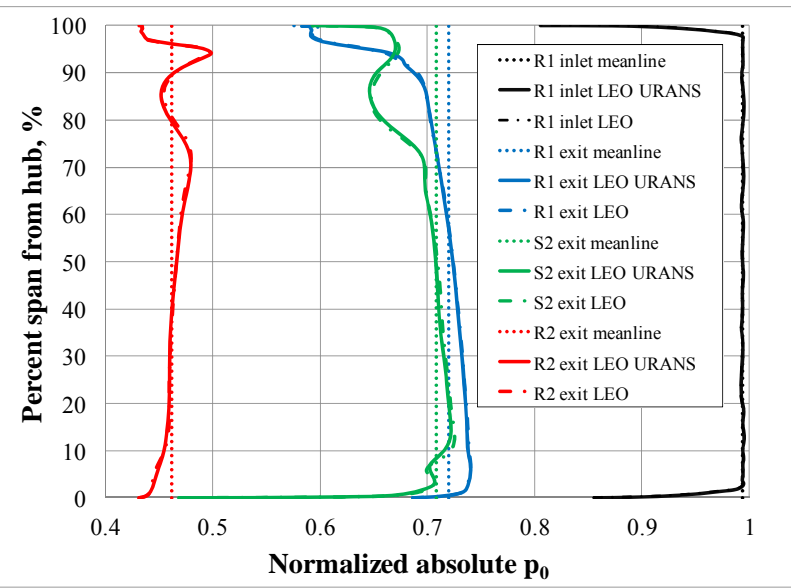

b. Off-design (takeoff, $N^{*}=100 \%$ )

Figure 13.-Spanwise profiles of normalized total-pressure, $p_{0}$, at R1 inlet and R1, S2, and R2 exits, showing comparison with meanline at design point (54\% $N^{\star}, 28 \mathrm{k}$-ft cruise) and off-design (100\% $N^{\star}, 2 \mathrm{k}$-ft takeoff). 


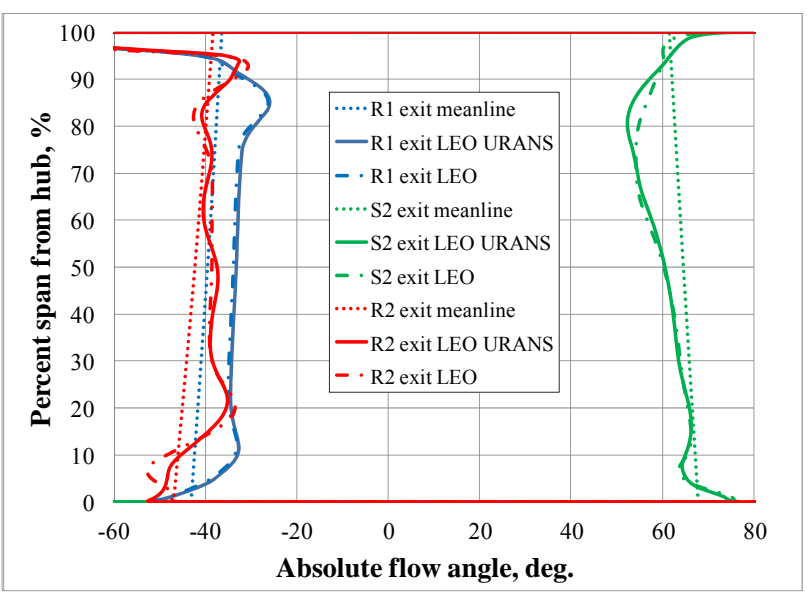

a. Design-point (cruise, $N^{*}=\mathbf{5 4 \%}$ )

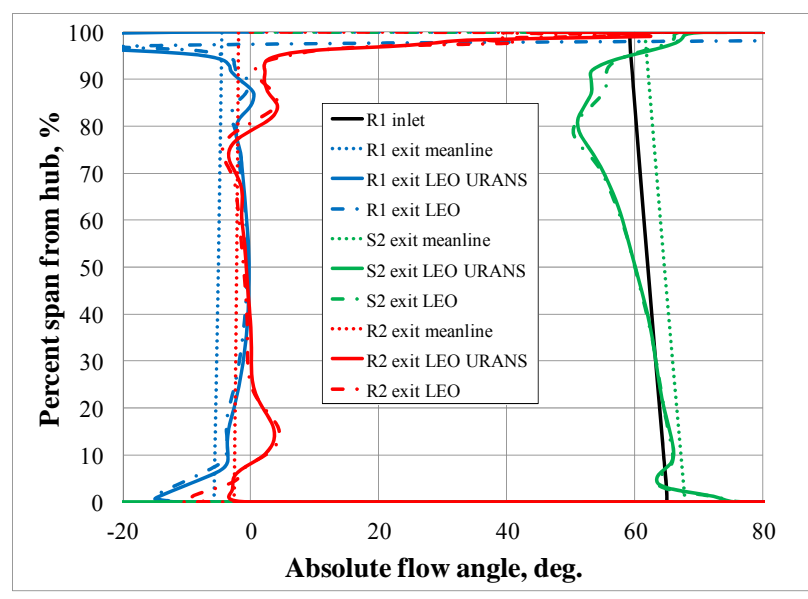

b. Off-design (takeoff, $N^{*}=100 \%$ )

Figure 14.--Spanwise profiles of absolute flow angle at R1 inlet and R1, S2, and R2 exits, showing comparison with meanline at design point (54\% $N^{\star}, 28 \mathrm{k}$-ft cruise) and off-design (100\% $N^{\star}, 2 \mathrm{k}$-ft takeoff).

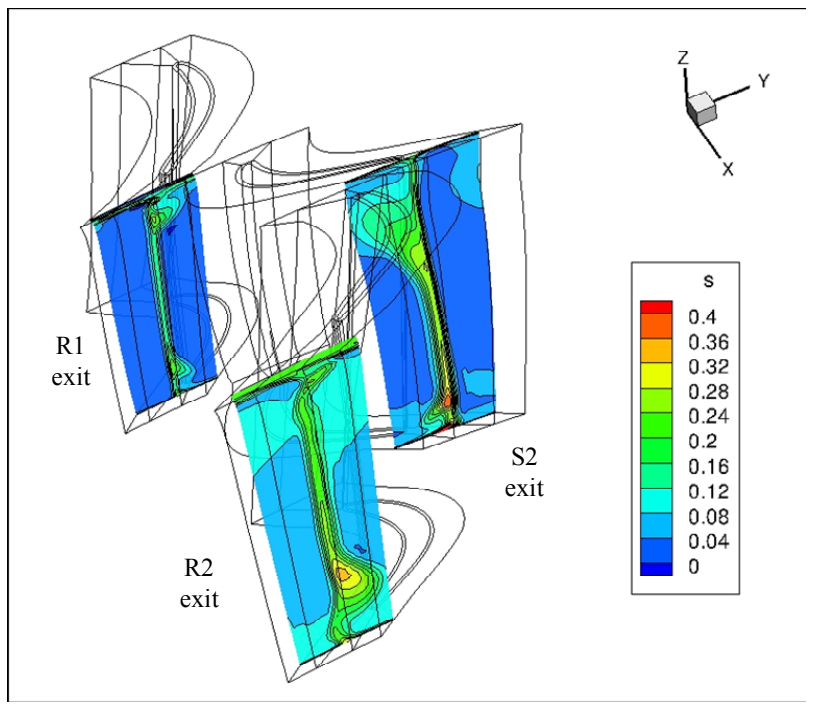

a. LEO mixing-plane

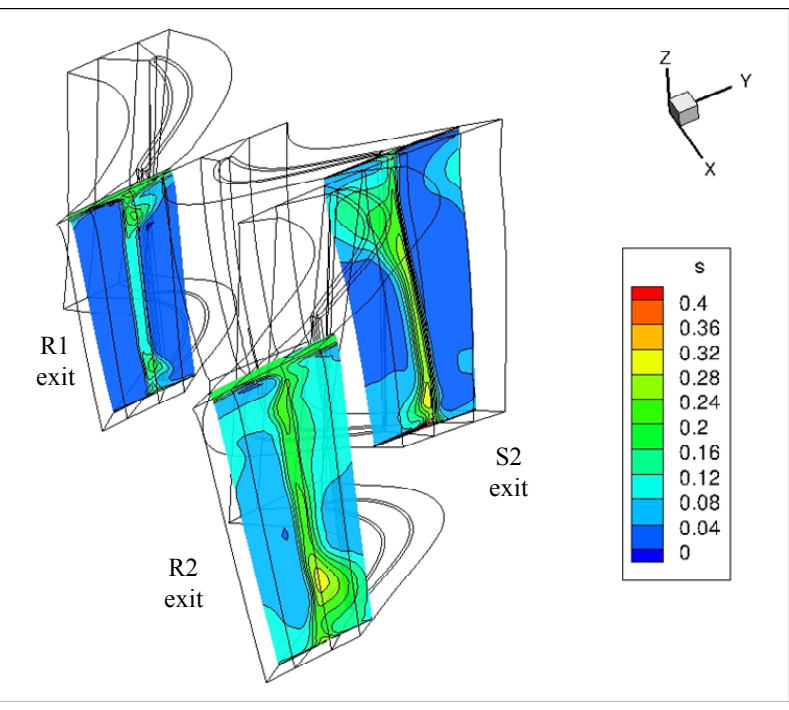

b. LEO URANS TA/AP

Figure 15.-Computed contours of entropy at the blade-row exit planes from LEO RANS/mixing-plane timeaveraged, average passage URANS calculations at design point (54\% N, $28 \mathrm{k}$-ft cruise). 


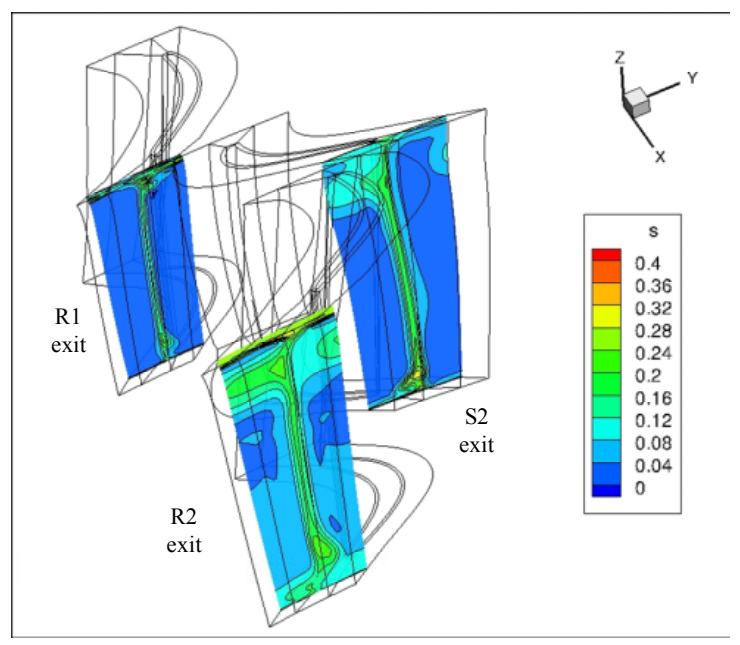

a. LEO mixing-plane

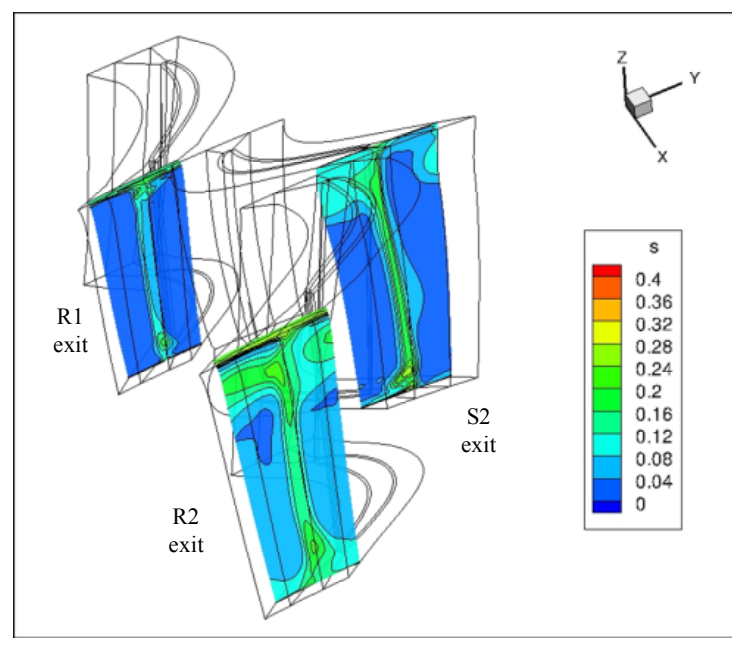

b. LEO URANS TA/AP

Figure 16.-Computed contours of entropy at the blade-row exit planes at off-design point from LEO RANS/mixing-plane time-averaged, average passage URANS calculations at takeoff ( $\left.2 \mathrm{k}-\mathrm{ft}, 100 \% N^{*}\right)$.

\subsection{Overall VSPT Performance}

The performance levels of the individual blade-rows and embedded stages, as predicted by the two RANS/mixing-plane solvers (SWIFT and LEO) and the LEO sector-periodic URANS solver, are compared to the meanline code levels in this section. Key blade-row and stage level metrics are reported in Table 4. The change in embedded 1.5-stage (R1/S2/R2) efficiency with speed is provided in Figure 17. The reported efficiencies and loss levels are based a spanwise mass-average of the pitchwise-averaged (mixed-out) flow at each section (k-plane). The performance levels of the mixing-plane codes are discussed first and the time-averaged, average-passage URANS levels follow. The trend of efficiency versus shaft-speed from the various solvers is presented in the final section.

As a preface to discussion on performance levels, it is noted that the rotor efficiencies of the LEO RANS/mixing-plane solution reported in Table 4 are considered high as a result of the non-physical flow (mixing-plane issue) introduced at the R1 and R2 exit rating planes. The potential impact on performance rating was substantiated by plotting the axial distribution of passage-averaged $p_{0}$ upstream and downstream of the rotor blade rows, whereby it was evident which axial stations were impacted by the non-physical flow. The contaminated R1 exit may have similarly caused high S2 loss levels to be reported for the LEO RANS/mixing-plane solution. The mixing-plane issue unfortunately limited the understanding that was to have been derived through the comparison of the predicted performance levels of the two mixing-plane solvers; and, more importantly, through comparison of the mixing-plane and URANS TA/AP results obtained on the same grid with the same flow solver. The SWIFT mixing-plane and the LEO URANS results did not suffer from the non-physical mixing-plane issue.

\subsection{RANS/Mixing-Plane Blade-Row Performance Levels}

Compared to the design- and off-design values from the meanline codes, the SWIFT mixing-plane predicted significantly lower R1 and S2 performance levels (Table 4). This was attributed to the difference in the computed work split in R1 and R2 by SWIFT as compared to meanline design-intent (Ref. 5). Unlike the meanline, the R2 efficiency of SWIFT decreased as shaft-speed was increased from $N^{*}=54$ to $100 \%$, a difference attributed to loss production induced at off-design by the pressure-side cove vortex that was not captured by the meanline model (Ref. 5). The S2 loss levels, though almost two times higher than the meanline levels, trended correctly with VSPT shaft-speed change. 
TABLE 4.-COMPARISON OF 3-D COMPUTATIONAL RESULTS WITH MEANLINE VALUES

\begin{tabular}{|c|c|c|c|c|c|c|c|c|}
\hline \multirow[b]{2}{*}{ Model } & \multicolumn{4}{|c|}{ Design $\left(54 \% N^{*}, \gamma=1.33\right)$} & \multicolumn{4}{|c|}{ Off-design $\left(100 \% N^{*}, \gamma=1.315\right)$} \\
\hline & $\begin{array}{l}\text { SWIFT } \\
\text { RANS }\end{array}$ & $\begin{array}{c}\text { LEO } \\
\text { RANS }\end{array}$ & $\begin{array}{c}\text { LEO } \\
\text { URANS }\end{array}$ & MEANLINE & $\begin{array}{l}\text { SWIFT } \\
\text { RANS }\end{array}$ & $\begin{array}{c}\text { LEO } \\
\text { RANS }\end{array}$ & $\begin{array}{c}\text { LEO } \\
\text { URANS }\end{array}$ & MEANLINE \\
\hline $\mathrm{R} 1 \eta_{\mathrm{tt}}$ & 0.9152 & 0.9414 & 0.9349 & 0.9275 & 0.9481 & 0.9597 & 0.9525 & 0.9530 \\
\hline $\mathrm{R} 2 \eta_{\mathrm{tt}}$ & 0.9329 & 0.9281 & 0.9121 & 0.9453 & 0.9258 & 0.9326 & 0.9219 & 0.9692 \\
\hline $\mathrm{R} 1 / \mathrm{S} 2 \eta_{\mathrm{tt}}$ & 0.8100 & 0.8454 & 0.8454 & 0.8682 & 0.8679 & 0.8912 & 0.8822 & 0.9080 \\
\hline $\mathrm{S} 2 / \mathrm{R} 2 \eta_{\mathrm{tt}}$ & 0.8444 & 0.8563 & 0.8463 & 0.9005 & 0.8269 & 0.8501 & 0.8383 & 0.9042 \\
\hline $\mathrm{R} 1 / \mathrm{S} 2 / \mathrm{R} 2 \eta_{\mathrm{tt}}$ & 0.8792 & 0.8952 & 0.8868 & 0.9152 & 0.9013 & 0.9170 & 0.9073 & 0.9448 \\
\hline $\mathrm{S} 2 \mathrm{Y}$ & 0.1414 & 0.1117 & 0.1157 & 0.0718 & 0.1326 & 0.1040 & 0.1088 & 0.0666 \\
\hline $\mathrm{S} 2 \Delta \mathrm{p}_{0} / \mathrm{p}_{0}$ & 0.0436 & 0.0361 & 0.0368 & 0.0222 & 0.0329 & 0.0266 & 0.0278 & 0.0165 \\
\hline $\mathrm{PR}_{\mathrm{TT}} \mathrm{R} 1 / \mathrm{S} 2 / \mathrm{R} 2$ & 2.1375 & 2.1355 & 2.1434 & 2.1454 & 2.1307 & 2.1301 & 2.1323 & 2.1555 \\
\hline $\begin{array}{l}\mathrm{TR}_{\mathrm{TT}} \\
\mathrm{R} 1 / \mathrm{S} 2 / \mathrm{R} 2\end{array}$ & 1.1779 & 1.1815 & 1.1804 & 1.1875 & 1.1756 & 1.1791 & 1.1772 & 1.1887 \\
\hline $\mathrm{Wc}, \mathrm{lb}_{\mathrm{m}} / \mathrm{s}$ & 12.942 & 12.874 & 12.797 & 12.868 & 12.423 & 12.224 & 12.169 & 12.060 \\
\hline
\end{tabular}

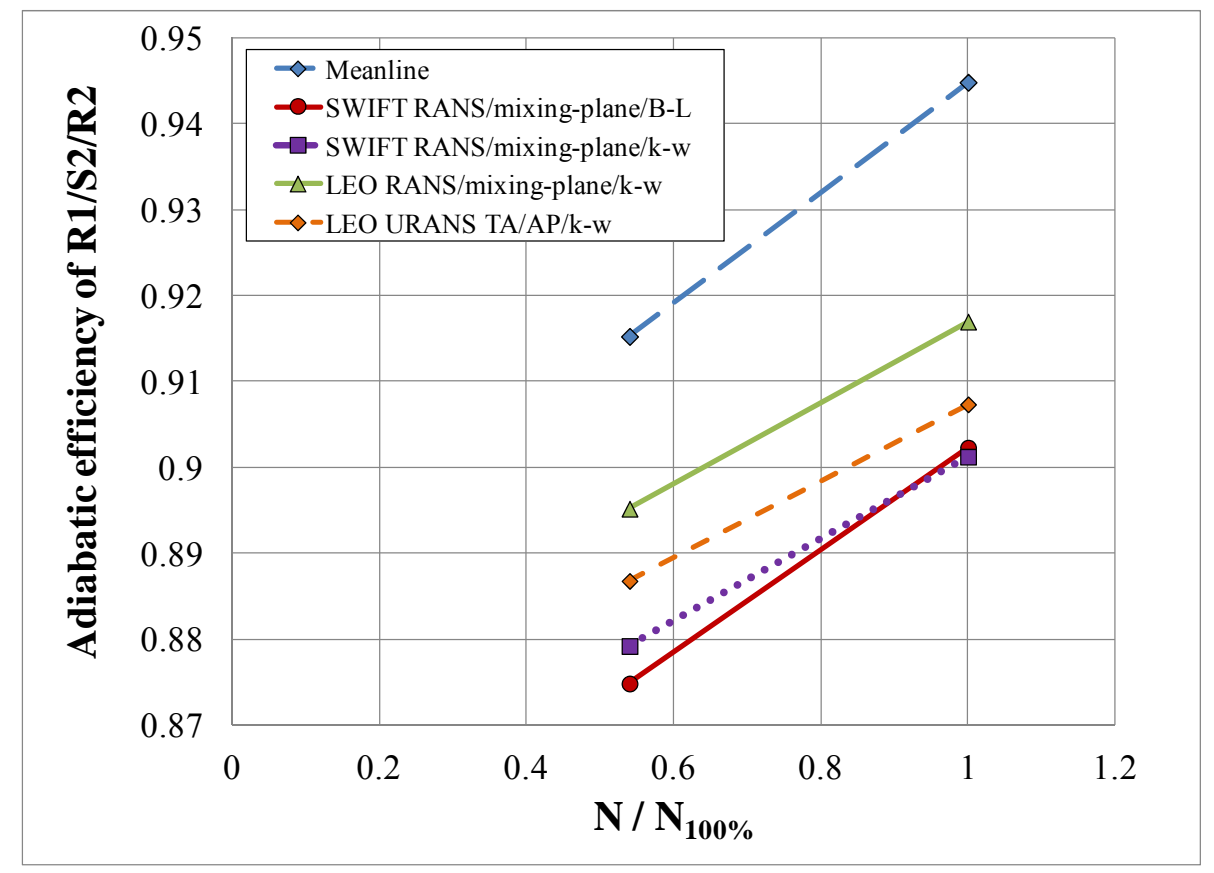

Figure 17.-Variation of embedded 1.5 stage (R1/S2/R2) adiabatic efficiency with speed from cruise $\left(54 \% N^{*}\right)$ to takeoff $\left(100 \% N^{*}\right)$ for SWIFT mixing-plane (BaldwinLomax and low-Re $\kappa-\omega)$, LEO mixing-plane (low-Re $\kappa-\omega)$, and LEO URANS TA/AP (low-Re $\kappa-\omega)$.

As noted in Section 4.0, the spanwise distributions of $T_{0}$ and $p_{0}$ from LEO mixing-plane were generally in better agreement with the meanline design-intent than those of SWIFT. The LEO RANS/mixing-plane predicted higher efficiency in R1 than in R2, in disagreement with the meanline design-intent where R1 efficiency is lower than R2 efficiency. The trends of increased R1 and R2 efficiency, and decreased S2 loss levels, with increased VSPT shaft-speed were in agreement with the meanline (Table 4).

\subsection{URANS Blade-Row Performance Levels}

The time-averaged, averaged-passage URANS results (Table 4) were generally in excellent agreement with results from the meanline codes, with the exception of the R2 efficiency, which was lower than design-intent. The trends of R1 and R2 efficiency and S2 loss levels with shaft-speed change were in agreement with the meanline. 
Arguably, a comparison of the LEO RANS/mixing-plane and LEO URANS results of Table 4 might suggest that the blade-row interaction effects have degraded R 2 efficiency by one point relative to the mixing-plane, and hence the overall embedded 1.5-stage performance. At off-design, the efficiency difference might be attributed, in part, to the impact of unsteadiness on vortical flows - particularly the tornado of the pressure-side-cove at off-design - manifested as increased entropy production and reduced work in the time-mean, average-passage flow. Similarly, a constituent of the efficiency-delta (RANS/mixing-plane versus URANS) at off-design $\left(N^{*}=100 \%\right)$ might arguably be attributed to the impact of unsteadiness on the S2 loss levels at the high negative incidence conditions of off-design operation. Unfortunately, the deleterious impact of the non-physical endwall flow in the LEO mixingplane solution makes the inferences tenuous.

\subsection{Efficiency Versus Shaft-Speed Trend of Embedded 1.5-Stage}

The predicted variation of embedded 1.5-stage (R1/S2/R1) efficiency with speed change for the various modeling approaches was provided in Figure 17. The difference in the embedded stage efficiencies of the SWIFT and LEO RANS/mixing plane solutions of the present study was largely attributed to the significantly different R1 efficiency levels and S2 loss levels. As shown, the results for both mixing-plane solvers agreed in terms of the predicted trend of efficiency versus speed. The fully turbulent SWIFT/mixing-plane with Baldwin-Lomax (fully turbulent option) from Reference 5 was repeated for reference. The slope of the efficiency-speed trend of the fully turbulent B-L solutions most closely agrees with the slope of the meanline. As in the earlier study (Ref. 5), the solutions using the lowRe $\kappa-\omega$ (RANS and URANS) have different slopes than the fully turbulent result, but nonetheless trend the same as the meanline.

As evident by comparing the time-averaged, average-passage URANS results with the mixing-plane results (Fig. 17), the unsteadiness due to blade-row interaction did not impact the qualitative trend of efficiency versus shaft-speed change. The VSPT, which was designed at the cruise shaft speed $N^{*}=54 \%$, showed increased efficiency at $N^{*}=100 \%$, in spite of the potential for performance degradation by unsteady forcing at this operating condition. As mentioned, an attribution of the difference between the LEO RANS/mixing-plane and URANS TA/AP efficiency levels (Fig. 17) to the effects of unsteadiness was unfortunately not substantiated herein.

\subsection{Conclusion}

RANS/mixing-plane and the time-averaged, averaged-passage URANS simulation results were compared at the design- and off-design operating points of a variable-speed power turbine (VSPT) for the NASA Large Civil Tilt-Rotor application. The impact of unsteadiness associated with blade-row interaction was assessed in term of its impact on efficiency and the trend of efficiency with shaft-speed change.

The unsteadiness was found to degrade work and efficiency levels in Rotor 2, which was most impacted by the upstream blade rows of the embedded R1/S2/R2 1.5-stage simulation. Quantification of the efficiency degradation (approximately 1 point) associated with unsteadiness, vis-à-vis comparison of efficiency predicted using the RANS/mixing-plane and sector-periodic URANS computations, was unfortunately rendered inconclusive. Introduction of non-physical flow at the rotor mixing-planes precluded a definitive back-to-back comparison of results from RANS/mixing-plane and URANS computations on the same grid, by the same flow solver (LEO).

The trend of efficiency with changing VSPT shaft speed from the URANS simulation, from $N^{*}=54 \%$ (28 k-ft, cruise) to $N^{*}=100 \%$ ( $2 \mathrm{k}$-ft, takeoff), agreed with the corresponding trends from the two RANS/mixing plane codes (SWIFT and LEO) and meanline codes used for turbine design. This key finding gives confidence to the turbine designer in their selection of optimum turbine design speed for minimizing mission fuel burn. 


\section{References}

1. Acree, C.W., Hyeonsoo, Y., and Sinsay, J.D., "Performance Optimization of the NASA Large Civil Tiltrotor," Proc. Int. Powered Lift Conf., London, UK, July 22-24, 2008.

2. Stevens, M.A., Handschuh, R.F., Lewicki, D.G., "Variable/Multispeed Rotorcraft Drive System Concepts," NASA/TM-2009-215456; also ARL-TR-4728, Mar., 2009.

3. D'Angelo, M., "Wide Speed Range Turboshaft Study," NASA/CR-1995-198380, Aug, 1995.

4. Welch, G.E., "Assessment of Aerodynamic Challenges of a Variable-Speed Power Turbine for Large Civil Tilt-Rotor Application," Proc. AHS Int. 66 ${ }^{\text {th }}$ Ann. Forum, TX, May, 2010; also NASA/TM-2010-216758, Aug, 2010.

5. Welch, G.E., "Computational Assessment of the Aerodynamic Performance of a Variable-Speed Power Turbine for Large Civil Tilt-Rotor Application," Proc. AHS Int. 67th Ann. Forum, May, 2011; also NASA/TM-2011-217124, Nov., 2011.

6. Suchezky, M. and Cruzen, G.S., "Variable-Speed Power Turbine for the Large Civil Tilt Rotor," NASA/CR-2012-217424, Feb. 2012.

7. Ford, A., Turner, E., Bloxham, M., Gegg, S., King, B., Harris, C., Bell, M. and Eames, D., "Variable-Speed Power-Turbine Component Research Plan," NASA/CR-2012-217423, Feb. 2012.

8. Howard, S.A., "Rotordynamic Feasibility of a Conceptual Variable-Speed Power Turbine Propulsion system for Large Civil Tilt-Rotor Applications," Proc. AHS Int. Forum 68, May, 2012; also NASA/TM-2012-217134, 2012.

9. Wilkerson, J.B. and Smith, R.L., "Aircraft System Analysis of Technology Benefits to Civil Transport Rotorcraft," NASA/CR-2009-214594, Jun, 2009.

10. Clark, J.P., Koch, P.J., Ooten, M.K., Johnson, J.J., Dagg, J., McQuilling, M.W., Huber, F., and Johnson, P.D., "Design of Turbine Components to Answer Research Questions in Unsteady Aerodynamics and Heat Transfer," AFRL-RZ-WP-TR-2009-2180, Sep, 2009.

11. Chima, R.V., "Explicit Multigrid Algorithm for Quasi-Three-Dimensional Viscous Flows in Turbomachinery," J. Propulsion and Power, 3 (5), Sep-Oct, 1987, pp. 397-405.

12. Wilcox, D.C., Turbulence Modeling for CFD, DCW Industries, Inc. La Canada, CA, 1994.

13. Ainley, D.G. and Mathieson, G.C.R., "An Examination of Flow and Pressure Losses in Blade Rows of Axial Turbines, British Aeronautical Research Council (ARC)," R\&M 2891, 1955.

14. Adamczyk, J.J., "Model Equation for Simulating Flows in Multistage Turbomachinery," ASME 85GT-226, 1985.

15. Rose, M., Schüpbach, P., Mansour, M., "The Thermodynamics of Wake Blade Interaction in Axial Flow Turbines: Combined Experimental and Computational Study,” ASME GT2009-59655, Jun, 2009.

16. Haselbach, F., Schiffer, H.-P., Horsman, M., Dressen, S., Harvey, N., and Read, S., "The Application of Ultra High Lift Blading in the BR715 LP Turbine,” J. Turbomachinery, 124, Jan, 2002, pp. 45-51.

17. Halstead, D.E., Wisler, D.C., Okishii, T.H., Walker, G.J., Hodson, H.P, Shin, H-W., "Boundary Layer Development in Axial Compressors and Turbines: Part 3 of 4-LP Turbines," J. Turbomachinery, 119, 1997, pp. 225.

18. Praisner, T.J. and Clark, J.P., "Predicting Transition in Turbomachinery-Part I: A Review and New Model Development," J. Turbomachinery, 129, Jan, 2007, pp. 1-13.

19. Snyder, C.A. and Thurman, D.R., "Gas Turbine Characteristics for a Large Civil Tilt-Rotor (LCTR)," Proc. AHS Int. 65 ${ }^{\text {th }}$ Ann. Forum, TX, May, 2009; also NASA/TM-2010-216089, Feb, 2010.

20. Gier, J., Franke, M., Hübner, N. and Shröder, T., "Designing LP Turbines for Optimized Airfoil Lift," J. Turbomachinery, 132, Jul, 2010, pp. 031008-1 to -12.

21. Hourmouziadis, J., "Aerodynamic Design of Low Pressure Turbines," in Blading Design for Axial Turbomachines, AGARD-LS-167, pp. 8-1 to 8-40, 1989. 
22. Chima, R.V., "Calculation of Multistage Turbomachinery Using Steady Characteristic Boundary Conditions," AIAA-98-0968, Jan. 1998; also NASA/TM-1998-206613, Jan, 1998.

23. Chima, R.V., “TCGRID 3-D Grid Generator for Turbomachinery-User's Manual and Documentation," Dec, 1999.

24. Baldwin, B.S. and Lomax, H., "Thin-Layer Approximation and Algebraic Model for Separated Turbulent Flows," AIAA-78-257, Jan, 1978.

25. Chima, R.V., "SWIFT Code Assessment for Two Similar Transonic Compressors," AIAA-20091058, Jan, 2009; also NASA/TM-2009-215520, Feb, 2009.

26. Ni, R-H, Humber, W., Fan, G., Johnson, P.D, Downs, J., Clark, J.P., Koch, P.J., "Conjugate Heat Transfer Analysis of a Film-Cooled Turbine Vane," ASME GT2011-45920, Jun, 2011.

27. Davis, R.L., Shang, T., Buteau, J., Ni, R-H., "Prediction of 3-D Unsteady Flow in Multi-Stage Turbomachinery using an Implicit Dual Time-Step Approach," AIAA-1996-2565, Jul, 1996. 


\begin{tabular}{|c|c|c|}
\hline \multicolumn{2}{|c|}{ REPORT DOCUMENTATION PAGE } & $\begin{array}{l}\text { Form Approved } \\
\text { OMB No. 0704-0188 }\end{array}$ \\
\hline \multicolumn{3}{|c|}{$\begin{array}{l}\text { The public reporting burden for this collection of information is estimated to average } 1 \text { hour per response, including the time for reviewing instructions, searching existing data sources, gathering and maintaining the } \\
\text { data needed, and completing and reviewing the collection of information. Send comments regarding this burden estimate or any other aspect of this collection of information, including suggestions for reducing this } \\
\text { burden, to Department of Defense, Washington Headquarters Services, Directorate for Information Operations and Reports (0704-0188), } 1215 \text { Jefferson Davis Highway, Suite } 1224 \text {, Anlington, VA } 22222-2302 \text {. } \\
\text { Respondents should be aware that notwithstanding any other provision of law, no person shall be subject to any penalty for failing to comply with a collection of information if it does not display a currently valid OMB } \\
\text { control number. } \\
\text { PLEASE DO NOT RETURN YOUR FORM TO THE ABOVE ADDRESS. }\end{array}$} \\
\hline $\begin{array}{l}\text { 1. REPORT DATE (DD-MM-YYYY) } \\
01-04-2012\end{array}$ & $\begin{array}{l}\text { 2. REPORT TYPE } \\
\text { Technical Memorandum }\end{array}$ & 3. DATES COVERED (From - To) \\
\hline \multirow{3}{*}{\multicolumn{2}{|c|}{$\begin{array}{l}\text { 4. TITLE AND SUBTITLE } \\
\text { Computational Study of the Impact of Unsteadiness on the Aerodynamic Performance of a } \\
\text { Variable-Speed Power Turbine }\end{array}$}} & 5a. CONTRACT NUMBER \\
\hline & & 5b. GRANT NUMBER \\
\hline & & 5c. PROGRAM ELEMENT NUMBER \\
\hline \multirow{3}{*}{\multicolumn{2}{|c|}{$\begin{array}{l}\text { 6. AUTHOR(S) } \\
\text { Welch, Gerard, E. }\end{array}$}} & 5d. PROJECT NUMBER \\
\hline & & 5e. TASK NUMBER \\
\hline & & $\begin{array}{l}\text { 5f. WORK UNIT NUMBER } \\
\text { WBS 877868.02.07.03.01.02.01 }\end{array}$ \\
\hline \multicolumn{2}{|c|}{$\begin{array}{l}\text { 7. PERFORMING ORGANIZATION NAME(S) AND ADDRESS(ES) } \\
\text { National Aeronautics and Space Administration } \\
\text { John H. Glenn Research Center at Lewis Field } \\
\text { Cleveland, Ohio 44135-3191 }\end{array}$} & $\begin{array}{l}\text { 8. PERFORMING ORGANIZATION } \\
\text { REPORT NUMBER } \\
\text { E-18113 }\end{array}$ \\
\hline \multirow{2}{*}{\multicolumn{2}{|c|}{$\begin{array}{l}\text { 9. SPONSORING/MONITORING AGENCY NAME(S) AND ADDRESS(ES) } \\
\text { National Aeronautics and Space Administration } \\
\text { Washington, DC 20546-0001 }\end{array}$}} & $\begin{array}{l}\text { 10. SPONSORING/MONITOR'S } \\
\text { ACRONYM(S) } \\
\text { NASA }\end{array}$ \\
\hline & & $\begin{array}{l}\text { 11. SPONSORING/MONITORING } \\
\text { REPORT NUMBER } \\
\text { NASA/TM-2012-217425 }\end{array}$ \\
\hline \multicolumn{3}{|c|}{$\begin{array}{l}\text { 12. DISTRIBUTION/AVAILABILITY STATEMENT } \\
\text { Unclassified-Unlimited } \\
\text { Subject Categories: } 01 \text { and } 02 \\
\text { Available electronically at http://www.sti.nasa.gov } \\
\text { This publication is available from the NASA Center for AeroSpace Information, 443-757-5802 }\end{array}$} \\
\hline
\end{tabular}

\section{SUPPLEMENTARY NOTES}

\section{ABSTRACT}

The design-point and off-design performance of an embedded 1.5-stage portion of a variable-speed power turbine (VSPT) was assessed using Reynolds-Averaged Navier-Stokes (RANS) analyses with mixing-planes and sector-periodic, unsteady RANS analyses. The VSPT provides one means by which to effect the nearly 50 percent main-rotor speed change required for the NASA Large Civil Tilt-Rotor (LCTR) application. The change in VSPT shaft-speed during the LCTR mission results in blade-row incidence angle changes of as high as $55^{\circ}$. Negative incidence levels of this magnitude at takeoff operation give rise to a vortical flow structure in the pressure-side cove of a high-turn rotor that transports low-momentum flow toward the casing endwall. The intent of the effort was to assess the impact of unsteadiness of blade-row interaction on the time-mean flow and, specifically, to identify potential departure from the predicted trend of efficiency with shaft-speed change of meanline and 3-D RANS/mixing-plane analyses used for design.

\section{SUBJECT TERMS}

Axial flow turbine; Low pressure turbine; Rotary wing; Tilt-rotor; Aerodynamics

\begin{tabular}{|c|c|c|c|c|}
\hline \multicolumn{3}{|c|}{ 16. SECURITY CLASSIFICATION OF: } & \multirow{2}{*}{$\begin{array}{l}\text { 17. LIMITATION OF } \\
\text { ABSTRACT } \\
\text { UU }\end{array}$} & \multirow{2}{*}{$\begin{array}{l}\text { 18. NUMBER } \\
\text { OF } \\
\text { PAGES } \\
25\end{array}$} \\
\hline $\begin{array}{l}\text { a. REPORT } \\
\mathrm{U}\end{array}$ & $\begin{array}{l}\text { b. ABSTRACT } \\
U\end{array}$ & $\begin{array}{l}\text { c. THIS } \\
\text { PAGE } \\
\text { U }\end{array}$ & & \\
\hline
\end{tabular}


